\title{
Evaluating Instructive Feedback as a Maintenance Procedure During Discrete-Trial Instruction
}

Jessica M. Cheatham

Follow this and additional works at: https://researchrepository.wvu.edu/etd

\section{Recommended Citation}

Cheatham, Jessica M., "Evaluating Instructive Feedback as a Maintenance Procedure During DiscreteTrial Instruction" (2017). Graduate Theses, Dissertations, and Problem Reports. 5339.

https://researchrepository.wvu.edu/etd/5339

This Thesis is protected by copyright and/or related rights. It has been brought to you by the The Research Repository @ WVU with permission from the rights-holder(s). You are free to use this Thesis in any way that is permitted by the copyright and related rights legislation that applies to your use. For other uses you must obtain permission from the rights-holder(s) directly, unless additional rights are indicated by a Creative Commons license in the record and/ or on the work itself. This Thesis has been accepted for inclusion in WVU Graduate Theses, Dissertations, and Problem Reports collection by an authorized administrator of The Research Repository @ WVU. For more information, please contact researchrepository@mail.wvu.edu. 
Evaluating Instructive Feedback as a Maintenance Procedure During Discrete-Trial Instruction

Jessica M. Cheatham

\author{
Thesis submitted to the \\ Eberly College of Arts and Sciences \\ at West Virginia University \\ in partial fulfillment of the requirements \\ for the degree of \\ Master of Science \\ in \\ Psychology \\ Regina Carroll, Ph.D. Chair \\ Karen Anderson, Ph.D. \\ Julie Hicks-Patrick, Ph.D. \\ Department of Psychology \\ Morgantown, West Virginia \\ 2016
}

Keywords: autism spectrum disorder; instructive feedback; skill acquisition; response maintenance

Copyright 2017 Jessica M. Cheatham 


\begin{abstract}
Evaluating Instructive Feedback as a Maintenance Procedure During Discrete-Trial Instruction

Jessica M. Cheatham
\end{abstract}

Instructive feedback is a procedure that involves presenting secondary targets during a learning trial. The child is not required to respond to the secondary targets, and if the child does respond the therapist does not provide differential consequences. Instructive feedback has been shown to increase the effectiveness and efficiency of discrete-trial instruction for children with autism. We evaluated maintenance of previously learned skills when they were and were not presented as instructive feedback during teaching sessions. We used an adapted-alternating treatments design to compare three conditions, in which previously learned skills were presented as secondary targets five times per week, once per week, and when previously learned skills were not presented during the learning trial. We measured the percentage of trials with a correct response during maintenance and follow-up sessions, which we conducted for nine weeks. We also measured the number of sessions and amount of teaching time required for participants to meet a pre-specified mastery criterion in conditions with and without instructive feedback. Finally, we measured the percentage of trials in which a participant repeated the therapist's presentation of the secondary target. Results indicate that presenting target responses as instructive feedback did not improve or reduce the efficiency of teaching sessions with non-target responses. We will discuss clinical implications, limitations, and suggestions for future research.

Keywords: autism spectrum disorder; instructive feedback; skill acquisition; skill maintenance 


\section{TABLE OF CONTENTS}

I. Introduction (pp. 1-12)
a. Discrete-trial instruction (pp. 2-4)
b. Response Maintenance (pp. 4-5)
c. Task Interspersal (pp. 5-8)
d. Instructive Feedback (pp. 8-12)
e. Purpose (pp. 12)

II. Method (pp. 12-25)

a. Participants, Settings, and Materials (pp. 13-15)

b. Dependent Measures and Data Collection (pp. 15-16)

c. Interobserver Agreement and Procedural Integrity (pp. 16-18)

i. Preference Assessment (pp. 18)

d. Experimental Design and General Procedures (pp. 18-22)

i. Teaching Target Responses (pp. 22)

ii. Teaching Non-target Responses (pp. 22-23)

iii. Maintenance (pp. 23)

1. Control (pp. 23-24)

2. Instructive Feedback Once per Week (pp. 24)

3. Instructive Feedback Five Times per Week (pp. 24-25)

iv. Follow-up (pp. 25)

III. Results (pp. 25-30)

IV. Discussion (pp. 30-35)

V. References (pp. 36-41) 
VI. Table 1: Target Responses for Each Participant by Condition (pp. 42)

VII. Figure Captions (pp. 43)

VIII. Figure 1: Diagram of experimental procedures (pp. 44)

IX. Figure 2: Percentage of trials with a correct response during teaching sessions with target (first panel) and non-target (second panel) responses, as well as percentage of trials with an echoic response for target responses during teaching sessions for non-target responses with instructive feedback (third panel) for Chad (pp. 45)

X. Figure 3: Average percentage of trials with a correct response during weekly maintenance sessions for target responses (first panel) and weekly follow-up sessions for target (second panel), and non-target responses (third panel) for Chad (pp. 46)

XI. Figure 4: Percentage of trials with a correct response during teaching sessions with target (first panel) and non-target (second panel) responses, as well as percentage of trials with an echoic response for target responses during teaching sessions for non-target responses with instructive feedback (third panel) for Kyle Set 1 (pp. 47)

XII. Figure 5: Average percentage of trials with a correct response during weekly maintenance sessions for target responses (first panel) and weekly follow-up sessions for target (second panel), and non-target responses (third panel) for Kyle Set 1 (pp. 48)

XIII. Figure 6: Percentage of trials with a correct response during teaching sessions with target (first panel) and non-target (second panel) responses, as well as percentage of trials with an echoic response for target responses during teaching sessions for non-target responses with instructive feedback (third panel) for Kyle Set 2 (pp. 49) 
XIV. Figure 7: Average percentage of trials with a correct response during weekly maintenance sessions for target responses (first panel) and weekly follow-up sessions for target (second panel), and non-target responses (third panel) for Kyle Set 2 (pp. 50)

XV. Appendices (pp. 51-56)

a. Appendix A: Glossary (pp. 51)

b. Appendix B: Operational Definitions (pp. 52-54)

c. Appendix C: Sample Primary Data Sheet (pp. 55)

d. Appendix D: Sample Secondary Data Sheet (pp. 56) 
Evaluating Instructive Feedback as a Maintenance Procedure during Discrete Trial Instruction Autism spectrum disorder (ASD) is a neurodevelopmental disorder characterized by persistent deficits in social communication and social interactions across contexts, as well as restricted, repetitive patterns of behavior, interests, and activities (American Psychiatric Association, 2013). One in 68 children have a diagnosis of ASD in the United States, which is a 38\% increase in prevalence since 2006 (Centers for Disease Control and Prevention [CDC], 2014). Early intensive behavioral intervention is a well-established, behavior-analytic treatment program for children with ASD. During early intervention programs, children learn in a highly structured, one-on-one setting for 20 to $40 \mathrm{hr}$ per week in the home or within an educational institution (Eikeseth, 2009; Lovaas, 1987; Rivard, Terroux, \& Mercier, 2014). Previous research has shown that early intensive behavioral intervention programs may improve IQ, academic performance, social skills, and adaptive behavior (Eikeseth, Klintwall, Jarh, \& Karlsson, 2012; Eikeseth, Smith, Jahr, \& Eldevik, 2007; Eldevik, et al., 2009).

For example, Eikeseth and colleagues (2007) compared outcomes for children with ASD who received either a behavioral ( $n=13 ; 8$ boys $)$ or an eclectic $(n=12 ; 11$ boys $)$ treatment in a public kindergarten or elementary school. Participants began treatment with a mean age of 5.5 years. Researchers based behavioral treatment on teaching procedures used in early intervention programs that were developed using principles of applied behavior analysis. Eclectic treatment used a combination of procedures commonly used in school settings for children with ASD, such as applied behavior analysis and sensory integration. Children in both groups received services for 28-29 hr each week, with a minimum of $20 \mathrm{hr}$ in one-on-one instruction outside the classroom. Participants completed follow-up assessments at a mean age of 8.3 years. Results showed greater improvements in IQ, adaptive functioning, and social behavior for children in 
the behavioral treatment group. These results support early intensive behavioral intervention as an effective strategy to improve behaviors for young children with ASD.

\section{Discrete-Trial Instruction}

During early intervention, children spend a substantial portion of time learning in highly structured, one-on-one teaching settings, such as discrete-trial instruction (Lerman, Valentino, \& LeBlanc, 2016). The components of discrete-trial instruction include (a) the presentation of an instruction, such as the therapist holding up a picture of a chair and saying, "What is it?" (b) the student's response to the instruction, such as the student saying, "Couch" (an incorrect response); (c) the presentation of a controlling prompt to help the student respond correctly, such as the therapist saying, "Chair"; (d) a consequence following the student's response, such as the therapist providing praise for a correct response or presenting a controlling prompt for an incorrect response; and (e) an inter-trial interval, which is a brief pause between successive trials (Smith, 2001).

Additional research is needed to identify and evaluate methods to improve the effectiveness and efficiency of discrete-trial instruction. The effectiveness of a teaching procedure refers to whether or not participants acquire skills targeted for instruction. Evaluating the effectiveness of a teaching procedure involves measuring the percentage of trials with a correct response. The efficiency of a teaching procedure refers to how quickly participants acquire skills targeted for instruction. Evaluating the efficiency of a teaching procedure involves measuring the duration of teaching time, the total number teaching trials, or the total number of instructional sessions required for participants to meet a pre-specified mastery criterion (Reichow \& Wolery, 2011). 
Over the last few decades, researchers have identified methods to improve the effectiveness of teaching procedures for children with ASD. For example, Charlop, Schreibman, and Thibodeau (1985) evaluated effects of using a prompt-delay procedure to teach seven children with ASD to request preferred items. During the prompt-delay procedure, the researcher presented a preferred item and then immediately modeled an appropriate request for that item. Researchers gradually increased the delay to the controlling prompt so the child had the opportunity to engage in an independent request. To evaluate the effectiveness of using a prompt-delay procedure to teach participants to request preferred items, researchers measured the percentage of trials with a correct response until a participant met mastery criterion. All participants met the mastery criterion for requesting preferred items, and generalized skills to untrained settings, individuals, and other preferred items

Prompt-delay procedures are established as effective (Charlop et al., 1985) and used in early-intervention programs; however, identifying and evaluating teaching procedures that are effective and efficient would help practitioners maximize learning so children with ASD can acquire more skills throughout their day. Recently, researchers have compared the effectiveness and efficiency of procedures used to correct errors during discrete-trial instruction (e.g., Carroll, Joachim, St. Peter, \& Robinson, 2015; Kodak et al., 2016; McGhan \& Lerman, 2013). For example, Carroll and colleagues (2015) compared the effectiveness and efficiency of four commonly used error-correction procedures to teach skills to three children with ASD and two children with ADHD. Skills taught varied across participants, but included reading sight words and expressively identifying features or functions of items. To compare the effectiveness of each procedure, researchers measured the percentage of trials with a correct response until participants met a pre-specified mastery criterion. To evaluate the efficiency of each procedure, 
researchers compared the total number of sessions, trials (including error-correction trials), and total teaching time in a condition for participants to reach mastery criterion. Results showed that multiple error-correction procedures were effective, but the efficiency of procedures varied across participants. Another component that influences the overall efficacy of teaching procedures is the ability for children to maintain previously learned skills, and at present, there are no evidence-based guidelines to help educators identify the most effective and efficient maintenance procedure. Therefore, researchers should also prioritize developing and systematically evaluating procedures to help children maintain skills learned during early intervention.

\section{Response Maintenance}

Response maintenance is the persistence of a response across time and in the absence of some or all procedures used to teach that response (Stokes \& Baer, 1977). A strategy suggested to promote response maintenance is reinforcement thinning, which involves gradually reducing reinforcement delivery for a target response (Cooper, Heron, \& Heward, 2007). For example, if a therapist were teaching a child to label colors, the therapist would provide praise and a preferred item for correct responses and present a controlling prompt for incorrect responses. The therapist would continue to conduct teaching sessions until the child met a pre-specified mastery criterion, and then gradually reduce how often s/he provided reinforcement for correct responses. After the child met a pre-specified criterion for responding with reinforcement thinning procedures, the therapist would discontinue teaching sessions for labeling colors. For example, when a therapist teaches a child to label colors, s/he would provide praise and a preferred item for every correct response. After the child responded correctly during $90 \%$ of trials across three consecutive sessions, then the therapist would provide praise and a preferred 
item following every one to three correct responses. If the child continued to respond correctly to $90 \%$ of trials across three consecutive sessions, s/he would provide praise and a preferred item following every four to six correct responses. She would continue to reduce how often s/he provided praise and a preferred item for correct responses until the child responded correctly without praise and preferred items. However, s/he would conduct regularly scheduled checks to monitor the maintenance of skills

Although reinforcement thinning is suggested to promote response maintenance (Cooper et al., 2007), it is unknown how frequently reinforcement-thinning procedures are used in clinical settings. Love and colleagues (2009) distributed an Internet survey to 211 practitioners working in early intervention programs to collect information about program characteristics, such as the number of hours each client received behavioral treatment each week, procedures to promote response maintenance, and procedures to facilitate skill acquisition. Ninety-eight percent of practitioners reported using procedures to promote the maintenance of previously learned skills on a daily or weekly basis, but the survey did not address the specific procedures used during maintenance programs. However, more specific information was provided about procedures used to facilitate skill acquisition, such as task interspersal.

\section{Task interspersal}

Seventy-one percent of early intervention programs use task interspersal during discretetrial instruction (Love, 2009). Task interspersal involves alternating between presenting previously learned skills and new skills during learning trials, typically according to a prespecified ratio. During a teaching session with task interspersal, the therapist requires a response to the instruction, and provides differential consequences for responding (e.g., Forbes, 2013; Henrickson, Rapp, Ashbeck, 2015; Majdalany, 2014; Volkert, 2008). For example, during 
teaching sessions with task interspersal, Henrickson and colleagues (2015) presented three previously learned skills prior to presenting a new skill (3:1 ratio). Therapists provided praise if the child responded correctly to a previously learned skill, and access to a preferred food, toy, or a token if the child responded correctly to a new skill.

Although a majority of early intervention programs report using task interspersal to facilitate skill acquisition (Love, 2009), results of recent research suggest that these procedures may be less efficient than other alternatives (Forbes, 2013; Henrickson et al., 2015; Majdalany et al., 2014). For example, Forbes and colleagues (2013) compared effects of a 3-min computerbased flashcard program to teach students to read words in conditions that did or did not include the presentation of known words during the program. Participants included one child with a functional delay and two children with a learning disability in reading. All participants were enrolled in an elementary special education classroom. Across conditions, the computer program presented words one at a time in random order. The researcher instructed students to read each of the words on the screen, and then to repeat the audio recording of the word. In a condition, the program presented fifteen unknown words and in the other condition the program presented 12 unknown words and three known words. To evaluate the efficiency of teaching procedures, researchers compared the cumulative number of unknown words acquired across conditions. Results indicated that including known words slowed learning rates for all three participants. These results indicate that using task interspersal may reduce instructional efficiency for children with ASD.

Majdalany and colleagues (2014) compared the effectiveness and efficiency of task interspersal and two additional teaching procedures for five children diagnosed with ASD and one child diagnosed with a pervasive developmental disorder not otherwise specified. 
Researchers compared the effectiveness of each procedure by evaluating the percentage of trials with a correct response. Researchers evaluated efficiency by comparing total teaching time for participants to reach mastery criterion. In each condition, participants learned to label five countries after seeing the shape of that country. Results indicated that all participants acquired responses in the condition with task interspersal in the most sessions and required the most teaching time. These results suggest that task interspersal may not increase the efficiency of instructional sessions. However, results of follow-up sessions suggest that task interspersal may influence maintenance of previously learned skills because some participants maintained the most correct responses in the condition with task interspersal.

More recently, Henrickson and colleagues (2015) compared task interspersal to another teaching procedure to evaluate effects on rate of skill acquisition, the number of skills students maintained for up to six weeks, and rate of problem behavior during teaching sessions for three children diagnosed with ASD. Researchers measured the number of sessions required for participants to meet a pre-specified mastery criterion, duration of sessions, percentage of trials with problem behavior, and number of targets maintained after mastery. Results indicated that task interspersal did not improve how quickly participants acquired skills relative to the other teaching procedure. Participants maintained skills across conditions. Researchers also observed similar rates of problem behavior across conditions. Overall, results of recent studies on task interspersal indicate that this procedure may be less efficient than other procedures used during discrete-trial instruction (Forbes, 2013; Henrickson et al., 2015; Majdalany et al., 2014). Considering that the majority of early-intervention clinics use task interspersal, which may not increase the efficiency of discrete-trial instruction, and that approximately $50 \%$ of earlyintervention clinics provide fewer than 20 hours of behavioral services each week (Love, 2009), 
other teaching procedures, such as instructive feedback, may be used to improve the efficiency of discrete-trial instruction.

\section{Instructive Feedback}

Instructive feedback is a teaching procedure that increases the efficiency and effectiveness of discrete-trial instruction. Instructive feedback involves presenting secondary targets (i.e., extra non-target skills) during a learning trial. However, with instructive feedback, the therapist does not require a response to secondary targets, and if the child does respond, the therapist does not provide differential consequences. Several studies have evaluated the use of instructive feedback to facilitate skill acquisition (Carroll \& Kodak, 2015; Reichow \& Wolery, 2011; Vladescu \& Kodak, 2013). Results of these studies have shown that when secondary targets were presented as instructive feedback during sessions, participants learned more skills in a similar amount of teaching time when compared to sessions without instructive feedback. Furthermore, instructive feedback did not interfere with participants' ability to learn skills taught directly (i.e., primary targets), and did not substantially influence session time (Holcombe, Wolery, Werts, \& Hrenkevich, 1993; Reichow \& Wolery; Vladescu \& Kodak; Werts, Wolery, Holcombe, \& Gast, 1995; Wolery, Cybriwsky, Gast, Boyle-Gast, 1991). This procedure is effective when the secondary target is presented during the consequence (i.e., end) or antecedent (i.e., beginning) portion of a trial (Vladescu \& Kodak). Instructive feedback effectively facilitates skill acquisition for students diagnosed with social-emotional problems (Werts, Wolery, Holcombe, \& Frederick, 1993), intellectual and learning disabilities (Gast, Doyle, Wolery, Ault, Kolenda, 1994), and typically developing students (Werts, Wolery, Venn, Demblowski, Doren, 1996). For example, Gast and colleagues (1994) conducted teaching sessions with primary targets and evaluated the effectiveness of presenting one to two 
secondary targets during the learning trial for four children with a mild intellectual disability. The primary target was a picture of a preferred location. Secondary targets were the street name and an activity associated with that location. Results showed that when one secondary target was presented, three of the four participants acquired primary and secondary targets. When two secondary targets were presented, participants acquired the primary targets and one of the secondary targets.

More recently, some research has demonstrated that instructive feedback may facilitate skill acquisition for students with ASD (Carroll \& Kodak, 2015; Loughrey, Betz, Majdalany, \& Nicholson, 2014; Reichow \& Wolery, 2011; Vladescu \& Kodak, 2013). For example, Reichow and Wolery compared effects of conducting teaching sessions for primary targets in conditions with and without instructive feedback. Participants included three children with ASD and one child with a developmental delay. Skills taught during the evaluation varied across participants, but included labeling pictures, numbers, and letters. Across conditions, therapists presented an instruction for a primary target and waited a specified period for the student to respond. If the student responded correctly, the therapist provided praise and a preferred item. In the condition with instructive feedback, the therapist presented a secondary target immediately after providing praise and a preferred item for responding correctly. If a response was not eligible for praise and a preferred item, then researchers did not present a secondary target. Researchers measured the percentage of trials with a correct response during teaching sessions for primary targets until participants met mastery criterion in each conditions. Since participants were not required to respond to secondary targets during teaching sessions, researchers conducted an additional session to measure the percentage of trials with a correct response for primary targets and for secondary targets. Participants acquired all primary targets, and all or most secondary targets. 
Results also showed that participants acquired primary targets in fewer sessions in the condition with instructive feedback compared to the condition without instructive feedback, suggesting that using instructive feedback during learning trials may facilitate skill acquisition.

Vladescu and Kodak (2013) replicated research on instructive feedback by evaluating the effectiveness and efficiency of presenting instructive feedback during teaching sessions for four children with ASD. Skills targeted for instruction varied across participants, but included either labeling items or completing fill-in-the-blank statements. During the study, researchers evaluated effects of providing instructive feedback before presenting an instruction for the skill taught directly (i.e., antecedent portion of the trial) and after providing praise and a preferred item (i.e., consequence portion of the trial). Researchers also evaluated effects of providing instructive feedback outside of a learning trial.

During teaching sessions, participants were not required to respond to the secondary targets; thus, researchers were unable to measure the percentage of trials with a correct response during sessions. Therefore, researchers conducted an additional session following every one to three teaching sessions to determine how quickly participants acquired secondary targets. Additionally, although a response to the presentation of the secondary target was not required, participants sometimes echoed the presentation of the secondary target, which potentially influenced the acquisition of secondary targets. To assess effects of echoic responses on acquisition of secondary targets, researchers collected data on the percentage of trials in which a participant repeated the therapist's presentation of instructive feedback. To compare effectiveness, researchers measured the percentage of trials with a correct response for primary and secondary targets. For efficiency, researchers collected data on session duration across conditions and compared the number of sessions required for participants to meet mastery 
criterion. Results indicated that participants acquired primary targets across conditions, and that three of the four participants acquired all or most of the secondary targets. Furthermore, results demonstrated no substantial differences in the effectiveness or efficiency of instruction across antecedent and consequence conditions. In addition, three of the four participants also acquired all or most secondary targets presented outside of learning trials. Participants also echoed a majority of secondary targets across conditions. This evaluation provides evidence that using instructive feedback increases the efficiency of instructional sessions because some participants could learn twice as many skills in a similar amount of time.

More recently, Loughrey et al. (2014) evaluated effects of presenting an intraverbal skill as instructive feedback while teaching a receptive skill to two children with ASD. Specifically, they taught participants to touch an item after hearing the name of that item, and presented the category name of that item as a secondary target during the consequence portion of the trial. For example, the therapist placed an array of pictures in front of the child and said, "Touch cashew." After the child responded correctly, the therapist provided praise (e.g., "Right!"), a preferred item, and then immediately stated the category name of that item by saying, "A cashew is a nut." In this example, the instruction for the skill taught directly was, "Touch cashew," and the secondary target was, "A cashew is a nut." Since participants were not required to respond to the secondary target, researchers conducted an additional session after each teaching session to monitor acquisition of secondary targets. During these sessions, the instructor showed the child a picture of a primary target, and then said, "A [item] is a ." For example, the therapist would hold up a picture of a cashew, and say, "A cashew is a ." If the child responded by saying "nut," then researchers counted that response as correct. Researchers measured percentage of trials with a correct response for primary and 
secondary targets. Results showed that all participants acquired primary and secondary targets and suggested that skills presented as a primary and secondary target do not have to be similar.

Prior research on instructive feedback suggests that some children with ASD may learn secondary targets without increasing the amount of instructional time (e.g., Loughry et al., 2014; Reichow \& Wolery, 2011; Vladescu \& Kodak, 2013). Therefore, presenting previously learned skills as instructive feedback may improve response maintenance without increasing instructional time. However, to date, no previous studies have evaluated effects of using instructive feedback as a maintenance procedure. With this procedure, the therapist would present an instruction for a primary target, and after providing praise and a preferred item for a correct response, the therapist would present a previously learned skill as a secondary target. The therapist would not require a response to the secondary target, and would not provide differential consequences for responding. Presenting previously learned skills, as secondary targets would not require additional prompts or reinforcement, and results of previous research suggest that it would have minimal influence on session time (Holcombe, Wolery, Werts, \& Hrenkevich, 1993; Reichow \& Wolery, 2011; Vladescu \& Kodak, 2013; Werts, Wolery, Holcombe, \& Gast, 1995; Wolery, Cybriwsky, Gast, Boyle-Gast, 1991).

\section{Purpose}

The purpose of this study was to extend the literature on instructive feedback by comparing the maintenance of previously learned skills when they were and were not presented as instructive feedback. To our knowledge, this was the first study evaluating effects of using instructive feedback as a maintenance procedure. A secondary purpose of this evaluation was to measure the number of sessions and amount of teaching time required for participants to meet a pre-specified mastery criterion in conditions with and without instructive feedback. 


\section{Method}

\section{Participants, Settings, and Materials}

Two children diagnosed with ASD participated. We recruited participants from a university-based early intervention clinic who were reported to have difficulty maintaining skills. Chad was a 7-year-11-month old Caucasian male who used five- to seven- word sentences to communicate and had been receiving discrete-trial instruction for 3.5 years. Staff members at the early intervention clinic, who were independent of this study, conducted the Verbal Behavior Milestones Assessment and Placement Program (VB-MAPP; Sundberg, 2008) with Chad when he was 7-years-9-months old. The VB-MAPP is a criterion-referenced skill assessment developed for individuals with ASD and other language delays that also serves as a curriculum guide for early intervention programs. The VB-MAPP consists of four components; however, we only used the Milestones Assessment to identify skills to target for instruction. The Milestones Assessment is a measure of 170 developmental milestones across three developmental stages that occur between the ages of 0-48 months. Following the assessment, Chad received a score of 103.5 out of 170 possible points. This score classified him as a Level 3 learner, indicating that his language skills are consistent with that of a typically developing child between the ages of 20-48 months. We conducted the Expressive Vocabulary Test-2 (EVT-2; Williams, 2007) with Chad when he was 6-years 10-months old. The EVT-2 is a normreferenced assessment that measures spoken word retrieval and expressive vocabulary for adults and children. Chad's results on the EVT-2 indicated an age equivalent of 2.6 years. Finally, we conducted the Peabody Picture Vocabulary Test-4 (PPVT-4; Dunn \& Dunn, 2007) with Chad when he was 7-years 11-months old. The PPVT-4 is a norm-referenced assessment used to 
measure listener vocabulary. Chad's results on the PPVT-4 indicated an age equivalent of 3.3 years.

Kyle was 5-year-4-month old Caucasian male who requested preferred items or activities with one word and had been receiving discrete-trial instruction for 1.9 years. Staff members at the early-intervention clinic, who were independent of this study, conducted the VB-MAPP with Kyle when he was 5-years-1-month old. He received a score of 51 out of 170 possible points, and classified as a Level 1 learner indicating that his language skills are consistent with that of a typically developing child between the ages of 0-18 months. Based on skills demonstrated during the VB-MAPP assessment, we decided not to conduct the EVT-2 with Kyle. We attempted to conduct the PPVT-4 with Kyle, but he did not pass the training phase so he was not eligible for testing.

Based on the results of language assessments, we selected skills to teach each participant. For each participant, we identified responses to teach as target responses and as non-target responses. To compare response maintenance of previously learned skills when they were and were not presented as instructive feedback, we taught target responses to serve as previously learned skills during subsequent sessions. After participants acquired target responses, we taught non-target responses. When sessions included instructive feedback, the therapist presented a target response during non-target teaching sessions. For Chad, target and non-target responses were answering what, who, and when questions, and for Kyle, target and non-target responses were labeling pictures of common objects (see Table 1).

We conducted all teaching sessions either in a private room at a university-based earlyintervention clinic, or in an on-campus laboratory. The room in which sessions were conducted contained tables, chairs, a video camera, a tripod, and teaching materials for each session. 
Teaching materials included pictures, timers, data sheets, pens, and preferred items (i.e., edibles and tangibles). A secondary observer sat at a separate table near the therapist and participant during a proportion of experimental sessions.

\section{Dependent Measures and Data Collection}

The therapist who conducted sessions also served as the primary observer. The primary observer collected data on participant responses in real time using a printed data sheet and a pen during the session. On some occasions, the primary observer collected data from video. Specific participant responses included, (a) correct responses, defined as providing a predetermined vocal response (e.g., saying "Horse" after being shown a picture of a horse) within $5 \mathrm{~s}$ of the therapist's instruction; (b) prompted responses, defined as providing the correct vocal response following the therapist's model prompt (e.g., saying, "Horse" after the therapist says, "Horse"); (c) incorrect responses, defined as saying any word or phrase other than the vocal response within $5 \mathrm{~s}$ of the therapist's instruction (e.g., saying "Dog" after being shown a picture of a horse); and (d) no responses, defined as not responding within $5 \mathrm{~s}$ of the therapist's instruction. For sessions with instructive feedback, we collected data on the percentage of trials with an echoic response, defined as the participant repeating the therapist's presentation of the target response within $5 \mathrm{~s}$ of the presentation of the target response. We collected data on echoic responses to evaluate effects of the participant repeating the therapist's presentation of secondary targets on maintenance of target responses.

We compared the percentage of trials with a correct response during non-target teaching sessions to determine the effectiveness of each procedure. To evaluate efficiency, we measured the number of teaching sessions and amount of teaching time required for participants to meet a pre-specified mastery criterion during target and non-target teaching sessions across conditions. 
We converted each dependent measure to a percentage of trials by dividing the number of trials with an occurrence of a participant response by the total number of trials in a session and multiplying by 100 . We also measured the total number of sessions and teaching time required for participants to reach a predetermined mastery criterion for sets of target and non-target responses.

\section{Interobserver Agreement and Procedural Integrity}

For each participant, a secondary observer independently collected interobserver agreement data on participant responses during an average of $40 \%$ (range, $30 \%$ to $50 \%$ ) of the total sessions, as well as procedural integrity during an average of $37 \%$ (range, $24 \%$ to $50 \%$ ) of the total sessions. To ensure that data collection procedures were reliable, the primary observer conducted training sessions on data collection procedures with undergraduate research assistants before they served as a secondary observer. During training, research assistants read definitions for participant responses and treatment integrity measures, and then answered questions about definitions. After research assistants were able to answer all questions accurately, the primary observer and the research assistant scored mock videos of sessions with programmed treatment integrity errors, one trial at a time, until agreement was at or above $92 \%$ with responses prerecorded by the primary therapist prior to training sessions. Then, secondary observers independently scored additional mock videos of sessions with programmed treatment integrity errors until agreement for participant responses and treatment integrity measures was at or above $92 \%$ for three consecutive sessions. After research assistants were reliable on data collection procedures, they were eligible to serve as a secondary observer.

We calculated interobserver agreement for correct, incorrect, and prompted participant responses for a trial, the number of error corrections for trial, and total session duration. For 
sessions with instructive feedback, we also calculated interobserver agreement for a participant echoic response during a trial. We scored participant responses on a trial-by-trial basis for each session by dividing the number of trials with exact agreement by the total number of trials in a session and multiplying by 100 . Mean agreement was $97 \%$ (range, $83 \%$ to $100 \%$ ) for Kyle and $98 \%$ (range, $85 \%$ to $100 \%$ ) for Chad.

For all conditions, the secondary observer collected data on treatment fidelity by recording if the therapist implemented specific components of the teaching procedure correctly. During all sessions, a correct response for attention was defined as the therapist presenting the instruction after Chad was oriented toward her or after Kyle made eye contact with the picture. A correct response for the instruction was defined as presenting the instruction exactly as it was written for Chad and not presenting an instruction for Kyle. During teaching sessions, a correct response for the prompt was defined as providing a controlling prompt if the child responded incorrectly or if the child did not respond within $5 \mathrm{~s}$. A correct response for reinforcement was defined as providing praise and $25 \mathrm{~s}$ access to a preferred item if the child responded correctly. During teaching sessions with instructive feedback, a correct response for providing instructive feedback was defined as presenting a target response as instructive feedback within $2 \mathrm{~s}$ of providing praise. A correct response for echoics was defined as withholding changes in facial expression for $5 \mathrm{~s}$ if the child repeated the therapists presentation of the target response. For baseline, maintenance, and follow-up conditions, the prompt was defined as withholding a controlling prompt if the child responded incorrectly or did not respond, and reinforcement was defined as providing praise and $25 \mathrm{~s}$ access to a preferred item for responding correctly to a previously learned skill. We calculated treatment integrity for each session by dividing the number of trials implemented correctly by the total number of trials in a session and multiplying 
by 100 . Mean treatment integrity was $97 \%$ (range, $83 \%$ to $100 \%$ ) for Kyle and $99 \%$ (range, $85 \%$ to $100 \%$ ) for Chad.

Preference assessment. We conducted a daily multiple-stimulus without replacement (MSWO; Higbee, Carr, \& Harrison, 2000) preference assessment before the first session of each day to determine which items to use during teaching sessions. During the daily MSWO, the therapist placed five items on the table equidistant apart and centered in front of the participant. The therapist then labeled each item and then presented the instruction, "Pick one." After the participant selected an item, the therapist let the participant play with that item for 10 to $15 \mathrm{~s}$ and then removed the item from the table. The therapist rearranged the remaining four items by moving the one on the far left to the far right, re-centered the array, and then presented the instruction, "Pick one." The therapist continued this procedure until the participant selected three items. The top three items identified during the preference assessment were used during teaching sessions.

For Kyle, before the first session of the day, we conducted a preference assessment with toys and another preference assessment with small pieces of food; for Chad, we only conducted a preference assessment with toys. We conducted additional preference assessments after every three to four teaching sessions, or when it appeared that the items were no longer preferred. For example, if the participant stopped interacting with the item during the reinforcement period, or requested a different item, we conducted an additional preference assessment immediately after that session.

\section{Experimental Design and General Procedures}

We used an adapted-alternating treatments design (Sindelair, Rosenberg, \& Wilson, 1985) to compare maintenance of previously learned skills when they were and were not 
presented as instructive feedback during teaching sessions for non-target responses. Specifically, we evaluated effects of conditions in which previously learned skills were presented as instructive feedback five times per week, once per week, or were not presented as instructive feedback during teaching sessions for non-target responses. We also measured the number of sessions and amount of teaching time required for participants to meet a prespecified mastery criterion in conditions with and without instructive feedback for the nontargeted responses.

An adapted-alternating treatments design is a single-subject, experimental design that involves the rapid alternation of two or more distinct treatments, when each treatment is applied to different target responses. With academic skills, this design can be used to compare performance with two or more instructional procedures when these procedures are used to teach different instructional sets of similar difficulty. Experimental control is shown with differential performance on at least two instructional sets. The inclusion of a non-instructional set, on which no instruction occurs, enhances control when performance with this set does not change. Figure 1 shows experimental procedures for each condition. First, we taught target responses in each condition. After participants acquired target responses across conditions, we discontinued teaching sessions for target responses and began teaching non-target responses. During nontarget teaching sessions, we presented previously learned target responses as secondary targets either once per week or five times per week, depending on the condition. For five weeks, we conducted a maintenance session for target responses. After five weeks, we discontinued teaching sessions for non-target responses and conducted follow-up sessions for target and nontarget responses for four additional weeks. 
For Kyle, we identified a set of nine target and nine non-target responses (Set 1), and for Chad, we identified a set of 12 target and 12 non-target responses. For each set, we assigned 3 targets to each condition for Kyle and 4 targets to each condition for Chad. We replicated this procedure with Kyle, so we identified an additional nine target and non-target responses for him (Set 2). We took a number of steps to equate the difficulty of responses across conditions. First, we conducted an echoic assessment to identify any words the participant echoed inconsistently or with poor articulation. During the echoics assessment, at the start of a trial, the therapist presented a vocal model of a target or non-target response. During every trial, the therapist provided praise if the participant repeated the vocal model, and after every one to three trials, the therapist also provided brief access to a preferred item. We presented up to three echoic trials for each target and non-target response. Based on the results of the echoic assessment, we excluded any response that the participant had difficulty echoing (e.g., the response was segmented), echoed inconsistently, or sounded too similar to another response. Then, we assigned target and non-target responses with a similar number of syllables to each condition and ensured responses in each set did not share similar stimulus characteristics (e.g., sound overlap).

The general teaching procedure we used was a constant prompt-delay procedure (Charlop, et al., 1985). With a constant-prompt delay procedure, the therapist gradually increased the delay between the instruction and controlling prompt. At the start of teaching sessions, the therapist used a 0 -s prompt delay. During teaching sessions with a 0 -s prompt delay, the therapist presented the instruction (Chad) or held up a picture and waited for the participant to make eye contact (Kyle) and then immediately modeled the correct response If the participant repeated the model, then the therapist delivered immediate praise and $25 \mathrm{~s}$ access to 
a preferred item. Once the participant engaged in a correct prompted response for $92 \%$ of trials for two consecutive sessions, the therapist increased the delay between the start of the trial and the controlling prompt to $5 \mathrm{~s}$.

During teaching sessions with a 5-s prompt delay, if the participant responded correctly within $5 \mathrm{~s}$, the therapist provided praise and brief access to a preferred item. If the participant responded incorrectly or did not respond within $5 \mathrm{~s}$, the therapist implemented an errorcorrection procedure (Carroll, et al., 2015). During the error-correction procedure, immediately following an incorrect or no response, the therapist provided a vocal model of the correct response, and then re-presented the trial. The therapist continued to re-present the trial until the participant responded correctly to the instruction. If the participant responded correctly during error correction, the therapist provided immediate praise and $25 \mathrm{~s}$ access to a preferred item. For example, the therapist might say, "Who cleans teeth?" and then wait $5 \mathrm{~s}$ for Chad to respond. If Chad answered incorrectly or did not respond within $5 \mathrm{~s}$, then the therapist would model the correct response by saying, "a dentist." If Chad repeated the therapist's model of the correct response by saying, "a dentist" the therapist would provide praise (e.g., "nice.”), and then re-present the trial until Chad answered the question correctly. The therapist would present the next trial following a brief inter-trial interval. To decrease the possibility of prompt dependence, once the participant responded correctly to $50 \%$ or more of the trials for two consecutive sessions, the therapist provided only praise for trials that required error correction for all subsequent sessions in that condition.

For each participant, we defined mastery criterion as responding correctly to at least $92 \%$ of trials for two consecutive sessions. For Kyle, we replicated the comparison with new 
sets of target and non-target response, so we identified nine additional target responses and nine additional non-target responses to teach him.

Each session consisted of 12 trials with each target or non-target response presented in a semi-random order three (Chad) or four (Kyle) times per session. To demonstrate that participants did not respond correctly before teaching, we conducted a minimum of three baseline sessions in each condition. At the start of the trial, the therapist waited for Chad to orient towards her, and then presented a question (e.g., "Who builds houses?"). For Kyle, at the start of a trial, the therapist held up a picture and waited for him to make eye contact with the picture. The therapist waited $5 \mathrm{~s}$ for the participant to respond. The therapist did not provide differential consequences for responding correctly, incorrectly, or not responding, and presented the next trial following a 1- to 3-s inter-trial interval. In order to promote continued responding during baseline in the absence of direct reinforcement, we provided an opportunity for the participant to respond to a previously learned skill following every one to three trials. If the participant responded correctly, the therapist provided praise and brief access to a preferred item. If the participant responded incorrectly, the therapist modeled the correct response and then ended the trial. For Kyle, previously learned skills included gross-motor imitation tasks (e.g., saying, "do this" and patting the table) and for Chad, previously learned skills were what, who, or when questions (e.g., asking, "Who flies planes?”).

Teaching target responses. The purpose of this condition was to teach a set of target responses that would later serve as previously learned skills during non-target teaching sessions. We conducted teaching sessions using the constant-prompt delay procedure described above. To equate the number of teaching sessions, we continued to conduct teaching sessions with all sets of targets until participants met mastery criterion with each set. After participants met mastery 
criterion, we discontinued teaching sessions for target responses and began conducting teaching sessions for non-target responses.

Teaching non-target responses. The purpose of this condition was to measure the number of sessions and amount of teaching time required for sets of non-target responses to reach a pre-specified mastery criterion during sessions with and without instructive feedback. After participants met mastery criterion for target responses across conditions, we conducted teaching sessions for non-target responses using a constant-prompt delay procedure. We conducted teaching sessions for non-target responses until participants met mastery criterion or until we had conducted a minimum of 25 teaching sessions in a condition.

Maintenance. The purpose of the maintenance condition was to evaluate maintenance of target responses while we were presenting target responses as instructive feedback. During maintenance sessions, the therapist did not provide differential consequences for responding correctly, incorrectly, or not responding, and presented the next trial following a 1- to 3- s intertrial interval. To maintain responding during maintenance sessions, following every one to three trials, the therapist provided an opportunity for the participant to respond to a previously learned skill. If the participant responded correctly, the therapist provided praise and brief access to a preferred item. If the participant responded incorrectly, the therapist modeled the correct response and then ended the trial. The therapist presented the next trial following a 1- to 3-s inter-trial interval. We conducted maintenance sessions with target responses for five weeks, within 30 min of every fifth teaching session for non-target responses.

Control. The purpose of this condition was to evaluate maintenance of target responses when target responses were not presented as instructive feedback during non-target teaching sessions. Each week, the therapist conducted teaching sessions for non-target responses using 
the constant-prompt delay procedure. That is, if the participant responded correctly to a trial for a non-target response, the therapist provided praise and brief access to a preferred item. If the participant responded incorrectly or did not respond within $5 \mathrm{~s}$, the therapist presented a controlling prompt, and then conducted error-correction trials until the participant responded correctly.

Instructive feedback once per week. The purpose of this condition was to evaluate maintenance of target responses when target responses were presented as instructive feedback once per week during non-target teaching sessions. During a trial with instructive feedback, the therapist presented a trial for a non-target response, and after the participant responded correctly to the non-target response, the therapist provided praise and $25 \mathrm{~s}$ access to a preferred item. Immediately after providing praise and a preferred item, the therapist presented instructive feedback for a previously learned target response. The therapist did not provide differential consequences if the participant engaged in an echoic response following the therapist's presentation of instructive feedback. For example, the therapist would begin a trial for a nontarget response by holding up a picture of a chair and waiting $5 \mathrm{~s}$ for a response. After the participant responded correctly by saying, "Chair," the therapist would provide praise and brief access to a preferred item. Immediately after providing praise, the therapist would present the target response as instructive feedback by holding up a picture of a shoe, waiting for the participant to make eye contact with the picture, and then saying, "Shoe." The therapist would not provide differential consequences if the participant engaged in an echoic response by saying, "Shoe."

Instructive feedback five times per week. The purpose of this condition was to evaluate maintenance of target responses when target responses were presented as instructive feedback 
five times per week during non-target teaching sessions. In this condition, we conducted teaching sessions with non-target responses five times per week and presented mastered target responses as instructive feedback during each session. We conducted sessions with instructive feedback using procedures described in the instructive feedback once per week condition. That is, during each trial the therapist presented a previously learned target response immediately after providing praise and a preferred item.

Follow-up. For target responses, the purpose of the follow-up condition was to evaluate maintenance when those responses were no longer presented as instructive feedback during non-target teaching sessions. For the non-target responses, the purpose was to assess correct responding following teaching sessions in the absence of prompts and reinforcement. We conducted follow-up sessions after we conducted 25 teaching sessions for non-target responses. Procedures for follow-up sessions were similar to those described for baseline sessions. That is, the therapist did not provide differential consequences for responding, but did provide praise and a preferred item for responding correctly to a previously learned skill.

\section{Results}

Figures 2 and 3 depict results for Chad and Figures 4, 5, 6, and 7 show results for Kyle. Figure 2 shows percentage of trials with a correct response during teaching sessions with target (first panel) and non-target (second panel) responses, as well as percentage of trials with an in which Chad echoed the target response during teaching sessions for non-target responses with instructive feedback (third panel) for Chad. During teaching sessions for target responses (first panel), Chad acquired target responses in the control condition following 10 teaching sessions with a total teaching time of $81 \mathrm{~min}$. For the once per week condition, Chad acquired target responses following five teaching sessions with a total teaching time of $41 \mathrm{~min}$. For the five 
times per week condition, Chad acquired target responses following 10 teaching sessions with a total teaching time of $77 \mathrm{~min}$. So participants would have the same amount of exposure to teaching sessions, we conducted teaching sessions for target responses in each condition until participants met mastery criteria across conditions. For Chad, we conducted 10 teaching sessions in each condition. Figure 2 (second panel) depicts the percentage of trials with a correct response during teaching sessions for non-target responses. Chad acquired non-target responses in the control condition following nine teaching sessions with a total teaching time of $67 \mathrm{~min}$. For the once per week condition, Chad acquired non-target responses following 10 teaching sessions with a total teaching time of $69 \mathrm{~min}$. For the five times per week condition, Chad acquired non-target responses following 6 sessions with a total teaching time of $44 \mathrm{~min}$. These results indicate that presenting target responses as instructive feedback did not improve or reduce the efficiency of teaching sessions with non-target responses. We continued to conduct teaching sessions with non-target responses until we conducted 25 teaching sessions in a condition ( 5 weeks). Figure 2 (third panel) shows the percentage of trials that Chad echoed the target responses when they were presented as instructive feedback during non-target teaching sessions. For the once per week condition, Chad engaged in an echoic response during an average of $78 \%$ (range, $100 \%$ to $67 \%$ ) of trials. For the five times per week condition, Chad engaged in an echoic response during an average of $86 \%$ (range, $100 \%$ to $42 \%$ ) of trials.

Figure 3 shows average percentage of trials with a correct response during weekly maintenance and follow-up sessions for Chad. During weekly maintenance sessions (first panel), Chad responded correctly to an average of $97 \%$ (range, 100\% to $92 \%$ ) of trials for the control condition, to an average of $97 \%$ (range, $100 \%$ to $92 \%$ ) of trials for the once per week condition, and to an average of $92 \%$ (range, $100 \%$ to $83 \%$ ) of trials for the five times per week 
condition. These results indicate that Chad maintained target responses in conditions with and without instructive feedback for five weeks. We conducted weekly follow-up sessions with target and non-target responses after participants met mastery criterion for non-target responses across conditions. When we conducted follow-up sessions for target responses (second panel), Chad responded correctly to an average of $96 \%$ (range, $100 \%$ to $92 \%$ ) of trials for the control condition, to $100 \%$ of trials for the once per week condition, and to an average of $98 \%$ (range, $100 \%$ to $92 \%$ ) of trials for the five times per week condition. This indicates that Chad continued to respond correctly to target responses after we stopped presenting target responses as instructive feedback. When we conducted follow-up sessions for non-target responses (third panel), Chad responded correctly to an average of $90 \%$ (range, $92 \%$ to $83 \%$ ) of trials for the control condition, to an average of $90 \%$ (range, $100 \%$ to $67 \%$ ) of trials for the once per week condition, and to an average of $98 \%$ (range, $100 \%$ to $92 \%$ ) of trials for the five times per week condition. These results show that Chad maintained non-target responses for four weeks in the absence of prompts and reinforcement.

Figure 4 (first panel) shows the percentage of trials during teaching sessions for target responses for Kyle Set 1. Kyle acquired target responses in the control condition following seven sessions with a total teaching time of $55 \mathrm{~min}$. For the once per week condition, Kyle acquired target responses following 12 sessions with a total teaching time of $107 \mathrm{~min}$. For the five times per week condition, Kyle acquired target responses following 16 sessions with a total teaching time of $152 \mathrm{~min}$. For Kyle, we conducted 16 teaching sessions in each condition. Figure 4 (second panel) depicts percentage of trials with a correct response during teaching sessions for non-target responses. Kyle acquired non-target responses for the control condition following 11 sessions with a total teaching time of $90 \mathrm{~min}$. For the once per week condition, 
Kyle acquired non-target responses following 12 sessions with a total teaching time of $104 \mathrm{~min}$, and for the five times per week condition following 14 sessions with a total teaching time of $133 \mathrm{~min}$. Results indicate that using instructive feedback as a maintenance procedure did not improve or reduce the efficiency of teaching sessions. We continued to conduct teaching sessions with non-target responses until we conducted 25 teaching sessions in each condition (5 weeks). Figure 4 (third panel) depicts the percentage of trials with an echoic response during teaching sessions for non-target responses with instructive feedback. For the once per week condition, Kyle engaged in an echoic response during an average of $18 \%$ (range, $25 \%$ to $8 \%$ ) of trials. For the five times per week condition, Kyle engaged in an echoic response during an average of $14 \%$ (range, $58 \%$ to $0 \%$ ) of trials.

Figure 5 shows average percentage of trials with a correct response during weekly maintenance and follow-up sessions for Kyle Set 1. During weekly maintenance sessions (first panel), Kyle responded correctly to an average of $87 \%$ (range, $100 \%$ to $58 \%$ ) of trials for the control condition, to an average of $68 \%$ (range, $100 \%$ to $33 \%$ ) of trials for the once per week condition, and to an average of $75 \%$ (range, $100 \%$ to $67 \%$ ) of trials for the five times per week condition. These results indicate that Kyle did not maintain target responses in conditions with and without instructive feedback. We conducted weekly follow-up sessions with target and nontarget responses after participants met mastery criterion across conditions for non-target responses. When we conducted follow-up sessions for target responses (second panel), Kyle responded correctly to an average of $83 \%$ (range, $100 \%$ to $58 \%$ ) of trials for the control condition, $90 \%$ (range, $100 \%$ to $83 \%$ ) of trials for the once per week condition, and to an average of $96 \%$ (range, $100 \%$ to $92 \%$ ) of trials for the five times per week condition. This indicates that Kyle responded correctly after we stopped presenting target responses as 
instructive feedback. When we conducted follow-up sessions for non-target responses (third panel), Kyle responded correctly to an average of $88 \%$ (range, $100 \%$ to $67 \%$ ) of trials for the control condition, $92 \%$ (range, $100 \%$ to $83 \%$ ) of trials for the once per week condition, and to an average of to an average of $88 \%$ (range, $100 \%$ to $58 \%$ ) of trials for the five times per week condition. These results show that Kyle maintained non-target responses for four weeks in the absence of prompts and reinforcement.

Figure 6 depicts percentage of trials with a correct response during teaching sessions with target (first panel) and non-target (second panel) responses, as well as percentage of trials with an echoic response during teaching sessions for non-target responses with instructive feedback (third panel) for Kyle Set 2. During teaching sessions for target responses, Kyle acquired target responses in the control condition following nine sessions with a total teaching time of $68 \mathrm{~min}$. For the once per week condition, Kyle acquired target responses in 13 sessions with a total teaching time of $99 \mathrm{~min}$. For the five times per week condition Kyle acquired target responses in 10 sessions with a total teaching time of 79 min. Results indicate that Kyle acquired target responses across conditions in approximately the same number of sessions. For Kyle, we conducted 13 teaching sessions in each condition. Figure 6 (second panel) shows percentage of trials with a correct response during teaching sessions for non-target responses. Kyle acquired non-target responses for the control condition following 8 sessions with a total teaching time of $67 \mathrm{~min}$. For the once per week condition, Kyle acquired non-target responses in 12 sessions with a total teaching time of $100 \mathrm{~min}$. For the five times per week condition, Kyle acquired non-target responses in 6 sessions with a total teaching time of 59 min. Results show that presenting previously learned skills as instructive feedback did not improve or reduce the efficiency of non-target teaching sessions. We continued to conduct teaching sessions with non- 
target responses until we conducted 25 teaching sessions in each condition ( 5 weeks). Figure 5 (third panel) shows the percentage of trials with an echoic response during teaching sessions for non-target responses with instructive feedback. Kyle echoed an average of $23 \%$ (range, $42 \%$ to $8 \%$ ) of target responses presented during the one time per condition. For the five times per week condition, Kyle engaged in an echoic response during an average of $14 \%$ (range, $33 \%$ to $0 \%$ ) of target responses presented during 5-s prompt delay teaching sessions.

Figure 7 depicts average percentage of trials with a correct response during weekly maintenance and follow-up sessions for Kyle Set 2. During weekly maintenance sessions (first panel), Kyle responded correctly to an average of $60 \%$ (range, $100 \%$ to $50 \%$ ) of trials for the control condition, to an average of $37 \%$ (range, $67 \%$ to $25 \%$ ) of trials for the once per week condition, and to an average of $48 \%$ (range, $83 \%$ to $0 \%$ ) of trials for the five times per week condition. These results indicate that Kyle did not maintain target responses in conditions with and without instructive feedback. During follow-up sessions for target responses (second panel), Kyle responded correctly to an average of $60 \%$ (range, $100 \%$ to $16 \%$ ) of trials for the control condition, $37 \%$ (range, $66 \%$ to $26 \%$ ) of trials for the once per week condition, and to an average of to an average of $48 \%$ (range, $83 \%$ to $0 \%$ ) of trials for the five times per week condition. This indicates that Kyle did not respond correctly to target responses after we stopped presenting those responses as instructive feedback. When we conducted follow-up sessions for non-target responses (third panel), Kyle responded correctly to an average of $60 \%$ (range, $83 \%$ to $42 \%$ ) of trials for the control condition, $38 \%$ (range, $67 \%$ to $0 \%$ ) of trials for the once per week condition, and to an average of to an average of $54 \%$ (range, $100 \%$ to $0 \%$ ) of trials for the five times per week condition. These results indicate that Kyle did not maintain non-target responses for four weeks in the absence of prompts and reinforcement. 


\section{Discussion}

The purpose of this study was to extend the literature on instructive feedback by comparing the maintenance of previously learned skills when they were and were not presented as instructive feedback. To our knowledge, this is the first study evaluating effects of using instructive feedback as a maintenance procedure. Chad and Kyle (Set 1) maintained target responses across conditions with and without instructive feedback, thus effects of presenting target responses as instructive feedback on the maintenance of those responses warrants further investigation. For Set 2, Kyle's responding was variable during maintenance and follow-up sessions within and across conditions, explanations of which will be discussed. Results of the current study indicate that presenting previously learned target responses as instructive feedback may facilitate response maintenance, however; participants maintained skills across conditions, so evidence to support use of this procedure is minimal. Additional research on the use of instructive feedback as a maintenance procedure is warranted because participants recruited for this evaluation were reported to have difficulty maintaining skills, but maintained skills across conditions during at least one comparison.

A secondary purpose of this evaluation was to measure the number of sessions and amount of teaching time required for participants to meet a pre-specified mastery criterion in conditions with and without instructive feedback. Previous research has shown that some participants acquire skills in conditions with instructive feedback in fewer sessions compared to conditions without instructive feedback (Carroll \& Kodak, 2015; Reichow \& Wolery, 2011). For example, Reichow and Wolery (2011) compared effects of conducting teaching sessions for primary targets in conditions with and without instructive feedback. Results indicated that three of the four participants acquired primary targets in fewer sessions and with less training time in 
the condition with instructive feedback. More recently, Carroll and Kodak (2015) evaluated effects of using instructive feedback to increase variability in intraverbal responses. In the condition with instructive feedback, participants acquired skills in fewer sessions and with less training time during at least one within-subject replication. However, these studies were not designed to evaluate effects of instructive feedback on the acquisition of primary skills so effects of instructive feedback on skill acquisition are unclear. Furthermore, in the current evaluation, there were no differences in the number of sessions and amount of training time required for participants to reach a pre-specified mastery criterion across conditions. Future research should continue to evaluate effects of instructive feedback on the acquisition of primary targets to improve the effectiveness and efficiency of instructional sessions for children with ASD.

To assess effects of echoic responses on maintenance of previously learned target responses, we collected data on the percentage of trials in which a participant repeated the therapist's presentation of the target response. Chad frequently engaged in echoic responses during teaching sessions with instructive feedback, and maintained target responses across conditions during maintenance and follow-up sessions. In the conditions with instructive feedback, Kyle infrequently engaged in echoic responses during Set 1 and Set 2. Chad and Kyle (Set 1) both maintained target responses presented as instructive feedback. Previous research has suggested that echoic responses may be a mechanism for the acquisition of skills presented as instructive feedback (Vladescu and Kodak, 2014). If results of future research support the use of instructive feedback as a maintenance procedure, then additional investigations should be conducted to determine the mechanisms responsible for maintenance of skills presented as 
instructive feedback and if those mechanisms are similar to those potentially responsible for skill acquisition.

Results of the maintenance and follow-up sessions for Chad and Kyle must be considered in light of some important limitations. First, we recruited participants from an earlyintervention clinic who were reported to have difficulty maintaining skills, but results of the evaluation indicate that Chad and Kyle (Set 1 only) maintained target responses with a high percentage of correct responses across conditions. Participants maintained skills across conditions, which limits conclusions about effects of instructive feedback on maintenance. If participants did not maintain skills well without direct teaching, we may have observed differential effects on responding during maintenance and follow-up sessions in conditions with and without instructive feedback. Rather than relying on self-report or indirect information to select participants, future researchers should conduct weekly sessions with participants to directly assess maintenance of previously learned skills after teaching sessions have been discontinued.

Second, a procedural integrity error likely accounts for the response variability observed during maintenance sessions for Kyle Set 2. Specifically, during the first maintenance session for Set 2, Kyle responded correctly to most trials the control and five times per week condition, and to some trials for the once per week condition. During the two- and three-week maintenance session, responding dropped to near zero across conditions, and during the four and five-week maintenance session, responding increased across conditions and maintained at comparable levels during follow-up sessions. During the two and three-week maintenance sessions, the therapist conducted sessions with inter-trial interval of less than $1 \mathrm{~s}$ rather than an inter-trial interval of 1- to 3- s. It is likely that Kyle learned to discriminate between prompting procedures 
used for teaching and maintenance sessions (Koegel, Dunlap, \& Dyer, 1980). More specifically, that the therapist would not provide a controlling prompt if Kyle responded incorrectly or did not respond during maintenance sessions. Prior to this procedural error, he had minimal exposure to differences in prompting procedures during teaching and maintenance sessions because he responded correctly to all or most of trials presented during maintenance Set 1 and during the one-week maintenance session for Set 2. When we identified this error, after each appointment, I watched experimental sessions from video to ensure that I conducted sessions with a 1 - to 3 -s inter-trial between successive trials. Considering the impact of this error on Kyle's responding, coupled with results of previous research, future researchers should consider including the duration of the inter-trial interval as a measure of procedural integrity.

Results of the current study suggest several areas for future research. First, reinforcement thinning is another strategy used to facilitate response maintenance in early intervention programs (Reichow et al., 2015). However, minimal research has been conducted to evaluate effects of this procedure on the maintenance of academic skills. Therefore, future research should evaluate procedures to determine the most effective and efficient way to thin reinforcement after the child has met a pre-specified mastery criterion. Future researchers should evaluate effects of thinning the schedule of reinforcement across different reinforcement parameters. Second, results of this evaluation indicate that presenting previously learned target responses as instructive feedback may facilitate response maintenance, however; participants maintained skills across conditions, so evidence to support use of this procedure is minimal. Future research should continue to evaluate procedures to promote the maintenance of previously learned skills in clinical settings, such as task interspersal. Results of Henrickson and colleagues (2015) suggest that task interspersal may also be an effective procedure to facilitate 
response maintenance. However, the study conducted by Henrickson and colleagues was designed to compare effects of different teaching procedures on skill acquisition, which limits conclusions that can be drawn about effects of task interspersal on response maintenance. If results of future studies indicate that task interspersal is an effective procedure to promote response maintenance, future researchers should systematically compare effects of task interspersal and instructive feedback on response maintenance. Specifically, researchers should compare the effectiveness and efficiency of each procedure by measuring the amount of training time and number of sessions required for participants to reach a pre-specified mastery criterion. 


\section{References}

American Psychiatric Association. (2013). Diagnostic and statistical manual of mental disorders (5th ed.). Arlington, VA: American Psychiatric Publishing.

Baer, D. M., Peterson, R. F., \& Sherman, J. A. (1967). The development of imitation by reinforcing behavioral similarity to a model. Journal of the Experimental Analysis of Behavior, 10, 405-416. doi:10.1901/jeab.1967.10-405

Centers for Disease Control and Prevention. (2016). Autism spectrum disorder (ASD): Data \& statistics. Retrieved from http://www.cdc.gov/ncbddd/autism/data.html

Carroll, R. A., \& Kodak, T. (2015). Using instructive feedback to increase response variability during intraverbal training for children with autism spectrum disorder. Analysis $O f$ Verbal Behavior, 31, 183-199. doi:10.1007/s40616-015-0039-x

Carroll, R. A., Joachim, B. T., St. Peter, C. C., \& Robinson, N. (2015). A comparison of errorcorrection procedures on skill acquisition during discrete-trial instruction. Journal of Applied Behavior Analysis, 48, 257-273. doi:10.1002/jaba.205

Charlop, M. H., Schreibman, L., \& Thibodeau, M. G. (1985). Increasing spontaneous verbal responding in autistic children using a prompt delay procedure. Journal of Applied Behavior Analysis, 18, 155-166. doi:10.1901/jaba.1985.18-155

Cooper, J. O., Heron, T. E., \& Heward, W. L. (2007). Applied behavior analysis. Upper Saddle River, NJ: Pearson Education.

Dunn, L. M., \& Dunn, D. M. (2007). Peabody picture vocabulary test manual (4th ed.). Minneapolis, MN: Pearson. 
Eikeseth, S., Smith, T., Jahr, E., \& Eldevik, S. (2007). Outcome for children with autism who began intensive behavioral treatment between ages 4 and 7: A comparison controlled study. Behavior Modification, 31, 264-278. doi:10.1177/0145445506291396

Eikeseth, S. (2009). Outcome of comprehensive psycho-educational interventions for young children with autism. Research in Developmental Disabilities, 30, 158-178. doi:10.1016/j.ridd.2008.02.003

Eikeseth, S., Klintwall, L., Jahr, E., \& Karlsson, P. (2012). Outcome for children with autism receiving early and intensive behavioral intervention in mainstream preschool and kindergarten settings. Research in Autism Spectrum Disorders, 6, 829-835. doi:10.1016/j.rasd.2011.09.002

Eldevik, S., Hastings, R. P., Hughes, J. C., Jahr, E., Eikeseth, S., \& Cross, S. (2009). Metaanalysis of early intensive behavioral intervention for children with autism. Journal of Clinical Child and Adolescent Psychology, 38, 439-450.

doi:10.1080/15374410902851739

Forbes, B. E., Skinner, C. H., Black, M. P., Yaw, J., Booher, J., \& Delisle, J. (2013). Learning rates and known-to-unknown flash-card ratios: Comparing effectiveness while holding instructional time constant. Journal of Applied Behavior Analysis, 46, 832-837. doi:10.1002/jaba.74

Gast, D. L., Doyle, P. M., Wolery, M., Ault, M. J., \& Kolenda, J. L. (1994). Instructive feedback: Effects of number and type. Journal Of Behavioral Education, 4, 313-334. doi:10.1007/BF01531985

Henrickson, M., Rapp, J. T., Ashbeck, A. H. (2015) Teaching with massed vs. 
interspersed trials: effects on acquisition, maintenance, and problem behavior. Behavioral Interventions, 3, 36-50. doi:10.1002/bin.1396

Higbee, T. S., Carr, J. E., \& Harrison, C. D. (2000). Further evaluation of the multiple-stimulus preference assessment. Research In Developmental Disabilities, 21, 61-73. doi:10.1016/S0891-4222(99)00030-X

Holcombe, A., Wolery, M., Werts, M. G., \& Hrenkevich, P. (1993). Effects of instructive feedback on future learning. Journal of Behavioral Education, 3, 359-285.

Kodak, T., Campbell, V., Bergmann, S., LeBlanc, B., Kurtz-Nelson, E., Cariveau, T., \& ... Mahon, J. (2016). Examination of efficacious, efficient, and socially valid errorcorrection procedures to teach sight words and prepositions to children with autism spectrum disorder. Journal of Applied Behavior Analysis, 49, 532-547. doi:10.1002/jaba.310

Koegel, R. L., Dunlap, G., \& Dyer, K. (1980). Intertrial interval duration and learning in autistic children. Journal of Applied Behavior Analysis, 13, 91-99. doi:10.1901/jaba.1980.13-91

Lerman, D. C., Valentino, A. L., \& LeBlanc, L. A. (2016). Discrete trial training. In R. Lang, T. Hancock, \& N Singh (Eds.), Early intervention for young children with autism spectrum disorder (pp. 47-83). New York, New York: Springer.

Loughrey, T. O., Betz, A. M., Majdalany, L. M., \& Nicholson, K. (2014). Using instructive feedback to teach category names to children with autism. Journal of Applied Behavior Analysis, 47, 425-430. doi:10.1002/jaba.123

Lovaas, O. I. (1987). Behavioral treatment and normal education and intellectual functioning in young autistic children. Journal of Consulting and Clinical Psychology, 55, 3-9. 
Love, J. R., Carr, J. E., Almason, S. M., \& Petursdottir, A. I. (2009). Early and intensive behavioral intervention for autism: A survey of clinical practices. Research in Autism Spectrum Disorders, 3, 421-428. doi:10.1016/j.rasd.2008.08.008

Majdalany, L. M., Wilder, D. A., Greif, A., Mathisen, D., \& Saini, V. (2014). Comparing massed-trial instruction, distributed-trial instruction, and task interspersal to teach tacts to children with autism spectrum disorders. Journal of Applied Behavior Analysis, 47, 657-662. doi:10.1002/jaba.149

McGhan, A. C., \& Lerman, D. C. (2013). An assessment of error-correction procedures for learners with autism. Journal of Applied Behavior Analysis, 46, 626-639. doi:10.1002/jaba. 65

Rapp, J. T., \& Gunby, K. (2016). Task interspersal for individuals with autism and other neurodevelopmental disorders. Journal of Applied Behavior Analysis, 49, 730-734. doi:10.1002/jaba.319

Reichow, B. (2012). Overview of Meta-Analyses on Early Intensive Behavioral Intervention for Young Children with Autism Spectrum Disorders. Journal of Autism and Developmental Disorders, 42, 512-520. doi:10.1007/s10803-011-1218-9

Reichow, B., \& Wolery, M. (2011). Comparison of progressive prompt delay with and without instructive feedback. Journal of Applied Behavior Analysis, 44, 327-340.

Rivard, M., Terroux, A., \& Mercier, C. (2014). Effectiveness of early behavioral intervention in public and mainstream settings: The case of preschool-age children with autism spectrum disorders. Research in Autism Spectrum Disorders, 8, 1031-1043. doi:10.1016/j.rasd.2014.05.010.

Sindelar, P. T., Rosenberg, M. S., \& Wilson, R. J. (1985). An adapted-alternating treatments 
design for instructional research. Education and Treatment of Children, 8, 67-76.

Smith, T. (2001). Discrete trial training in the treatment of autism. Focus on Autism and Other Developmental Disabilities, 16, 86-92. doi:10.1177/108835760101600204

Stokes, T. F., \& Baer, D. M. (1977). An implicit technology of generalization. Journal of Applied Behavior Analysis, 10, 349-367. doi:10.1901/jaba.1977.10-349

Sundberg, M. (2008). Verbal behavior milestones assessment and placement program. Concord, CA: AVB Press.

Vladescu, J. C., \& Kodak, T. M. (2013). Increasing instructional efficiency by presenting additional stimuli in learning trials for children with autism spectrum disorders. Journal of Applied Behavior Analysis, 46, 805-816. doi:10.1002/jaba.70

Volkert, V. M., Lerman, D. C., Trosclair, N., Addison, L., \& Kodak, T. (2008). An exploratory analysis of task-interspersal procedures while teaching object labels to children with autism. Journal of Applied Behavior Analysis, 41, 335-350. doi:10.1901/jaba.2008.41335

Werts, M. G., Wolery, M., Holcombe, A., \& Frederick, C. (1993). Effects of instructive feedback related and unrelated to the target behaviors. Exceptionality, 4, 81-95.

Werts, M. G., Wolery, M., Holcombe, A., \& Gast, D. L. (1995). Instructive feedback: Review of parameters and effects. Journal of Behavioral Education, 5, 55-75. doi:10.1007/BF02110214

Werts, M. G., Wolery, M., Venn, M. L., Demblowski, D., \& Doren, H. (1996). Effects of transition-based teaching with instructive feedback on skill acquisition by children with and without disabilities. The Journal of Educational Research, 90, 75-86.

doi:10.1080/00220671.1996.9944448 
Williams, K. T. (2007) Expressive vocabulary test (2nd ed.). Circle Pines, MN: AGS Publishing.

Wolery, M., Cybriwsky, C., Gast, D. L., \& Boyle-Gast, K. (1991). Use of constant prompt delay and attentional responses with adolescents. Exceptional Children, 57, 462-474.

Wolery, M., Werts, M. G., \& Holcombe, A. (1993). Reflections on “effects of instructive feedback related and unrelated to the target behaviors." Exceptionality, 4, 117-123. doi:10.1207/s15327035ex0402_5 
Table 1.

Target Responses for Each Participant by Condition

\begin{tabular}{|c|c|c|c|c|}
\hline \multirow{2}{*}{ Participant } & \multirow{2}{*}{ Task } & \multirow{2}{*}{ Condition } & \multicolumn{2}{|c|}{ Target Stimuli } \\
\hline & & & Target Responses & Non-target Responses \\
\hline \multirow{6}{*}{ Chad } & \multirow{6}{*}{$\begin{array}{l}\text { What and } \\
\text { who } \\
\text { questions }\end{array}$} & Control & $\begin{array}{l}\text { What do you put in your } \\
\text { dresser? (Clothes) } \\
\text { Where is your dresser? (In } \\
\text { the bedroom) } \\
\text { What do you wear at the } \\
\text { beach? (A swimsuit) } \\
\text { When do you go to the } \\
\text { beach? (The summer) }\end{array}$ & $\begin{array}{l}\text { What is Christmas? (A } \\
\text { holiday) } \\
\text { When is Christmas? } \\
\text { (December) } \\
\text { Where do you put } \\
\text { pictures? (In a frame) } \\
\text { Who takes pictures? (A } \\
\text { photographer) }\end{array}$ \\
\hline & & IF $1 \mathrm{x}$ & $\begin{array}{l}\text { Where do babies sleep? } \\
\text { (In a crib) }\end{array}$ & $\begin{array}{l}\text { What do you cut with? } \\
\text { (Scissors) }\end{array}$ \\
\hline & & & $\begin{array}{l}\text { What do babies drink } \\
\text { from? (A bottle) } \\
\text { What do you put on a } \\
\text { cake? (Frosting) } \\
\text { Where do you eat cake? } \\
\text { (at a birthday party) }\end{array}$ & $\begin{array}{l}\text { Who cuts hair? (A } \\
\text { barber) } \\
\text { When do you eat eggs? } \\
\text { (At breakfast) } \\
\text { Who lays eggs? (A } \\
\text { chicken) }\end{array}$ \\
\hline & & IF $5 x$ & $\begin{array}{l}\text { Where do carrots grow? } \\
\text { (In the ground) } \\
\text { Who eats carrots? (A } \\
\text { rabbit) } \\
\text { What do you put in a } \\
\text { lunchbox? (Crackers) } \\
\text { Where do you bring your } \\
\text { lunchbox? (To school) }\end{array}$ & $\begin{array}{l}\text { Who catches fish? (A } \\
\text { fisherman) } \\
\text { What do fish eat? } \\
\text { (Worms) } \\
\text { Where is the moon? (In } \\
\text { the sky) } \\
\text { What color is the } \\
\text { moon? (White) }\end{array}$ \\
\hline & & & Set 1 & \\
\hline & & Control & Apple, tree, fish & Cake, rock, phone \\
\hline \multirow[t]{5}{*}{ Kyle } & Labeling & IF $1 x$ & Hat, block, chicken & Bowl, plant, mouse \\
\hline & & IF $5 x$ & Cow, juice, marker & Key, truck, drum \\
\hline & & Control & $\begin{array}{l}\text { Set } 2 \\
\text { Hot dog, flag, car }\end{array}$ & Bed, leaf, spoon \\
\hline & $\begin{array}{l}\text { Labeling } \\
\text { pictures }\end{array}$ & IF $1 \mathrm{x}$ & Scissors, doll, pig & Pear, tent, rake \\
\hline & & IF $5 x$ & Comb, plate, lion & Socks, book, zebra \\
\hline
\end{tabular}

Note. IF $1 \mathrm{x}=$ Instructive feedback once per week; IF $5 \mathrm{x}=$ Instructive feedback five times per week 


\section{Figure Captions}

Figure 1. Diagram of experimental procedures

Figure 2. Percentage of trials with a correct response during teaching sessions with target (first panel) and non-target (second panel) responses, as well as percentage of trials with an echoic response for target responses during teaching sessions for non-target responses with instructive feedback (third panel) for Chad.

Figure 3. Average percentage of trials with a correct response during weekly maintenance sessions for target responses (first panel) and weekly follow-up sessions for target (second panel), and non-target responses (third panel) for Chad.

Figure 4. Percentage of trials with a correct response during teaching sessions with target (first panel) and non-target (second panel) responses, as well as percentage of trials with an echoic response for target responses during teaching sessions for non-target responses with instructive feedback (third panel) for Kyle Set 1.

Figure 5. Average percentage of trials with a correct response during weekly maintenance sessions for target responses (first panel) and weekly follow-up sessions for target (second panel), and non-target responses (third panel) for Kyle Set 1.

Figure 6. Percentage of trials with a correct response during teaching sessions with target (first panel) and non-target (second panel) responses, as well as percentage of trials with an echoic response for target responses during teaching sessions for non-target responses with instructive feedback (third panel) for Kyle Set 2.

Figure 7. Average percentage of trials with a correct response during weekly maintenance sessions for target responses (first panel) and weekly follow-up sessions for target (second panel), and non-target responses (third panel) for Kyle Set 2. 


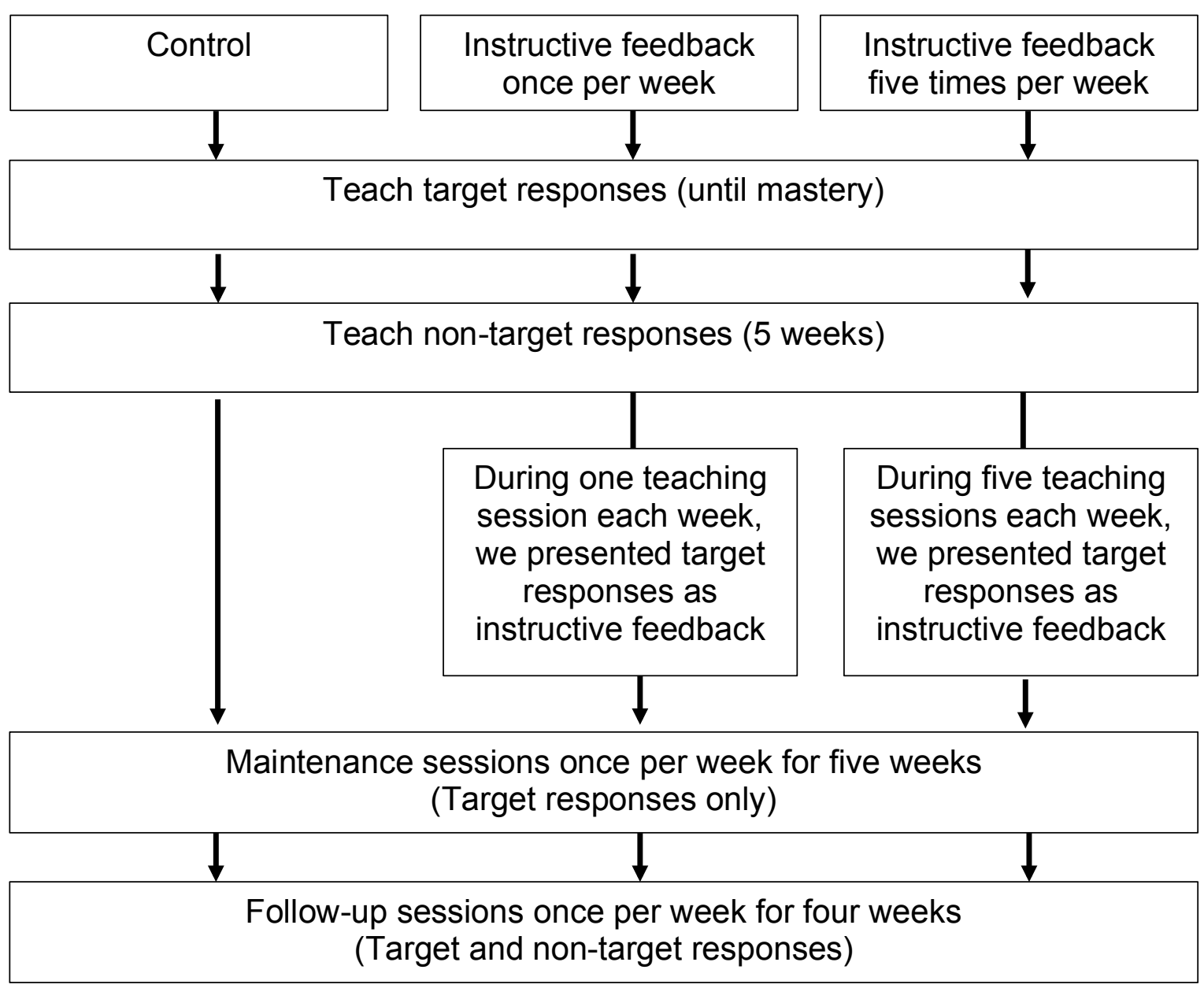

Figure 1. Diagram of experimental procedures 


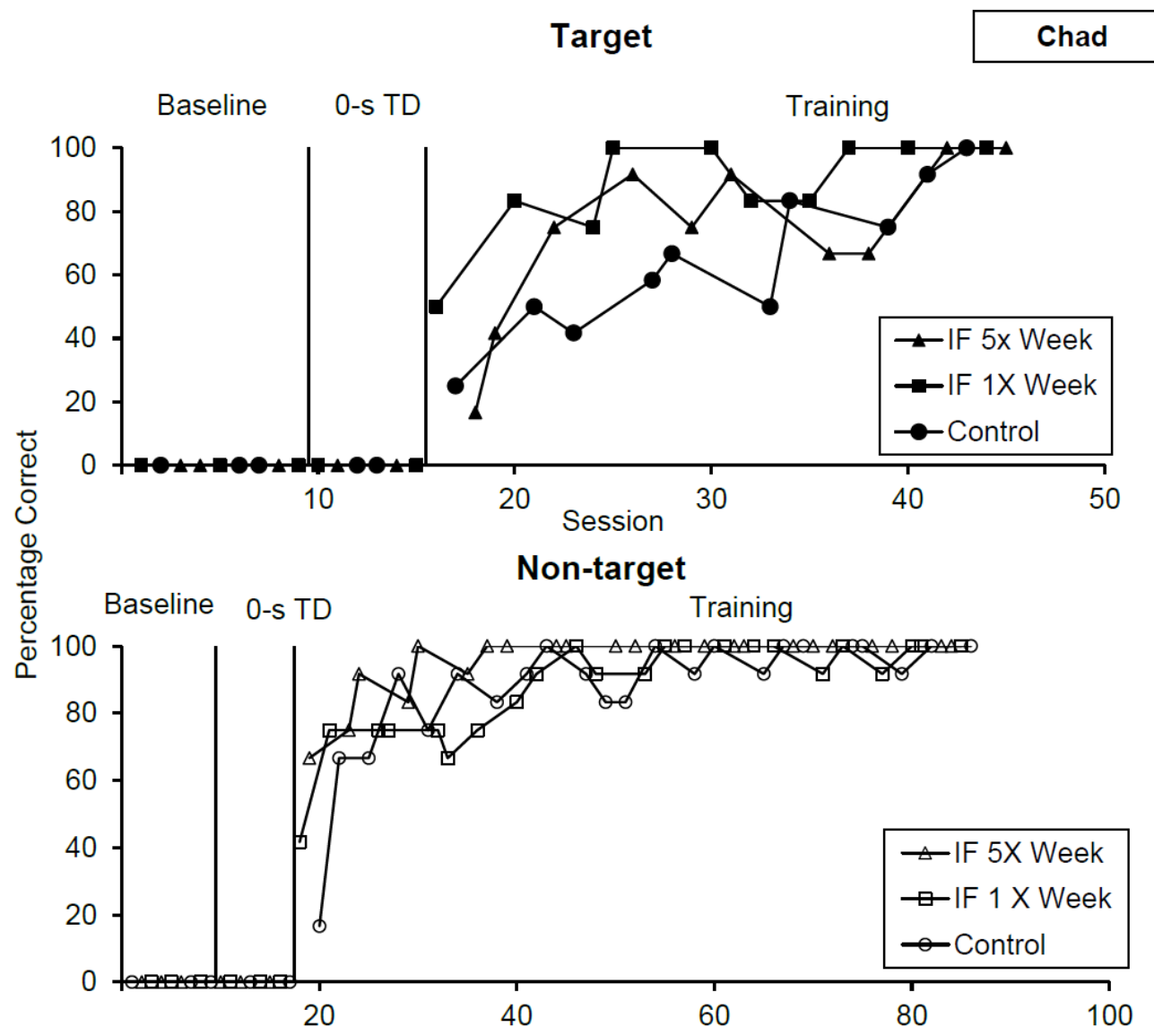

Echoic Responses

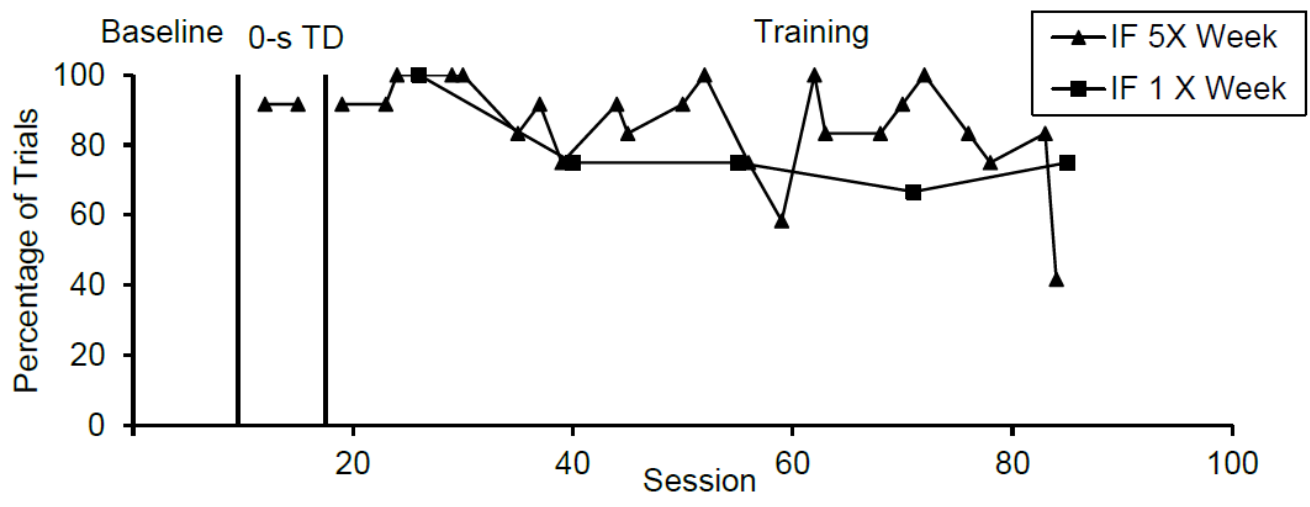

Figure 2. Percentage of trials with a correct response during teaching sessions with target (first panel) and non-target (second panel) responses, as well as percentage of trials with an echoic response for target responses during teaching sessions for non-target responses with instructive feedback (third panel) for Chad. 

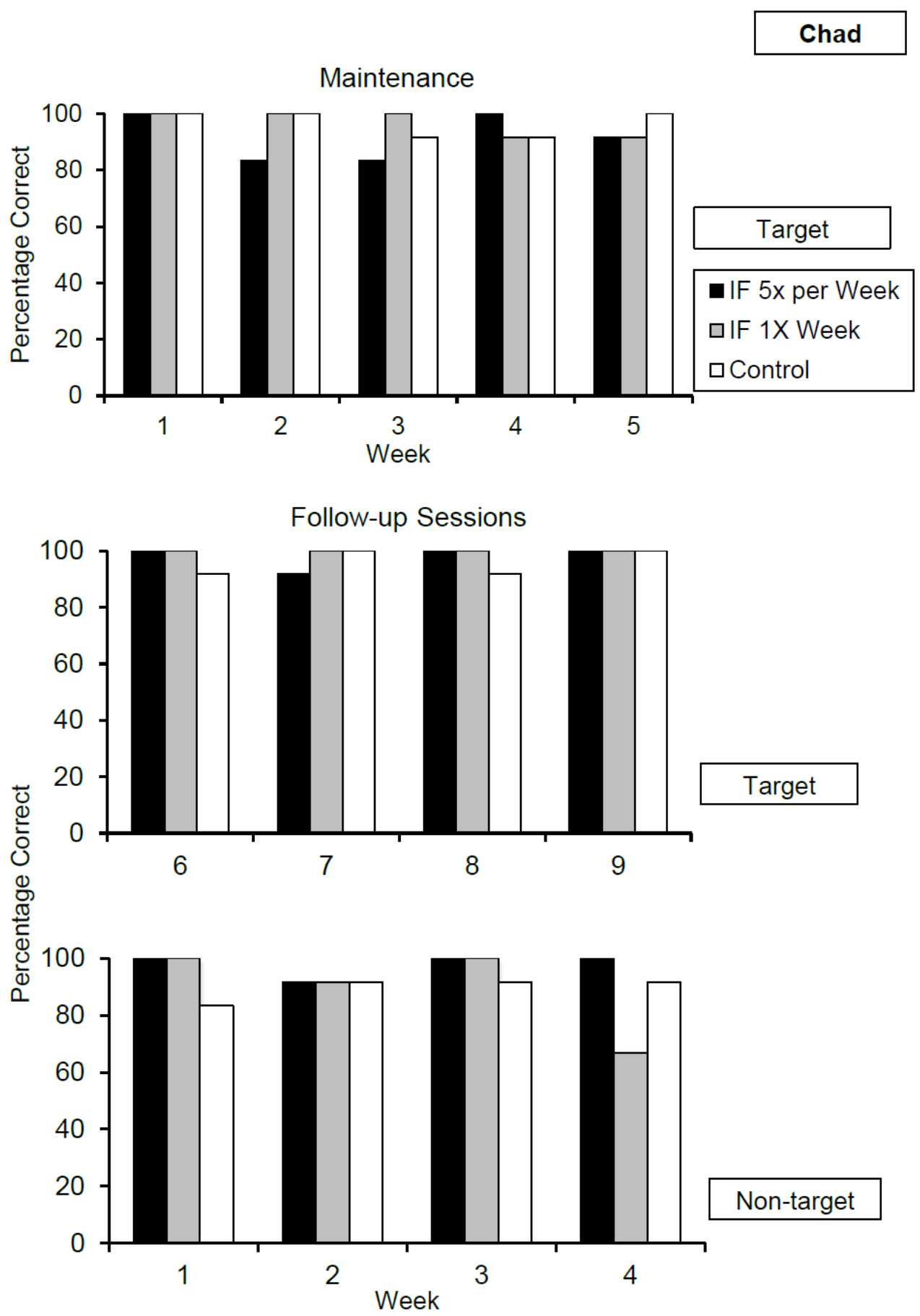

Figure 3. Average percentage of trials with a correct response during weekly maintenance sessions for target responses (first panel) and weekly follow-up sessions for target (second panel), and non-target responses (third panel) for Chad. 


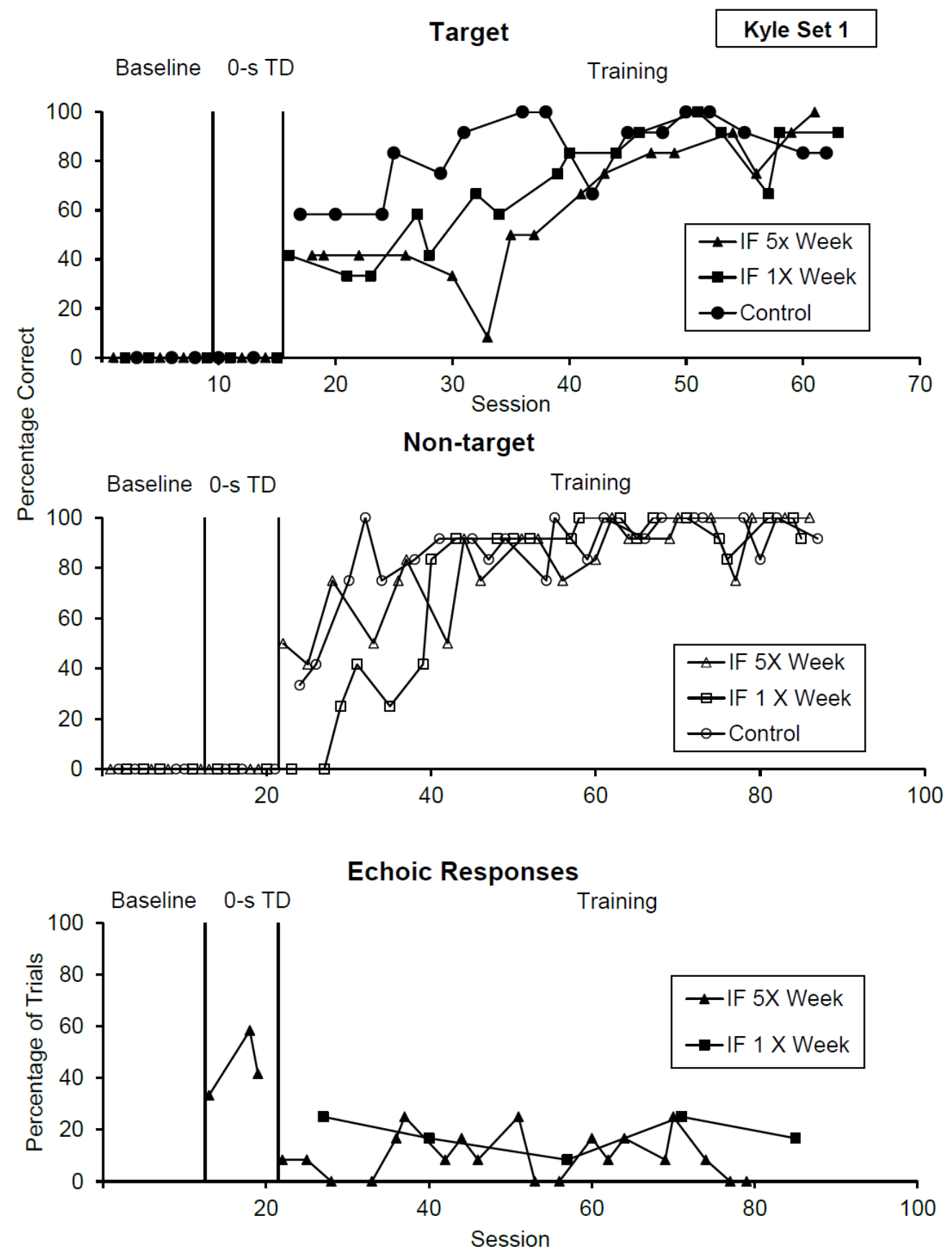

Figure 4. Percentage of trials with a correct response during teaching sessions with target (first panel) and non-target (second panel) responses, as well as percentage of trials with an echoic response for target responses during teaching sessions for non-target responses with instructive feedback (third panel) for Kyle Set 1. 

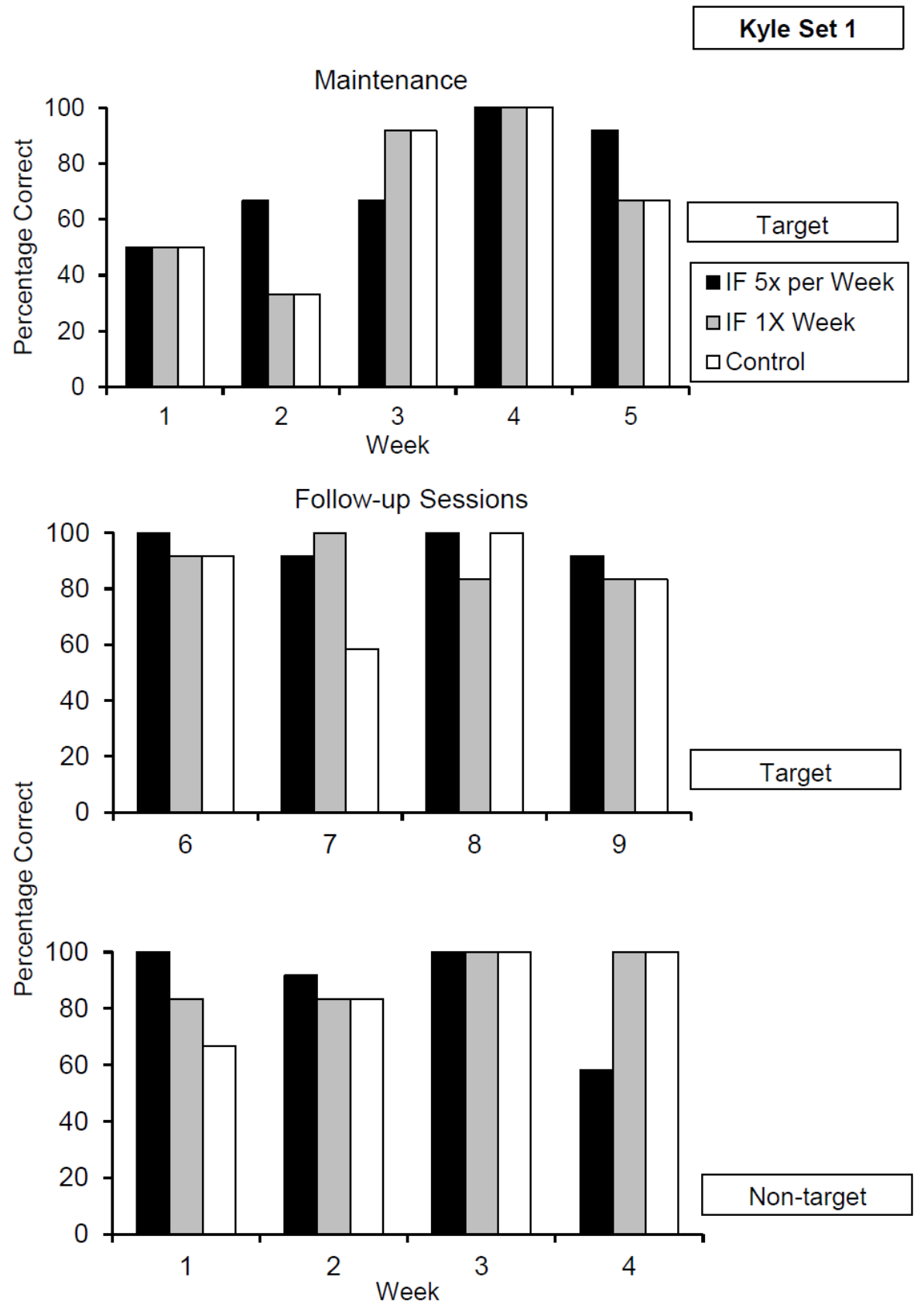

Figure 5. Average percentage of trials with a correct response during weekly maintenance sessions for target responses (first panel) and weekly follow-up sessions for target (second panel), and non-target responses (third panel) for Kyle Set 1. 


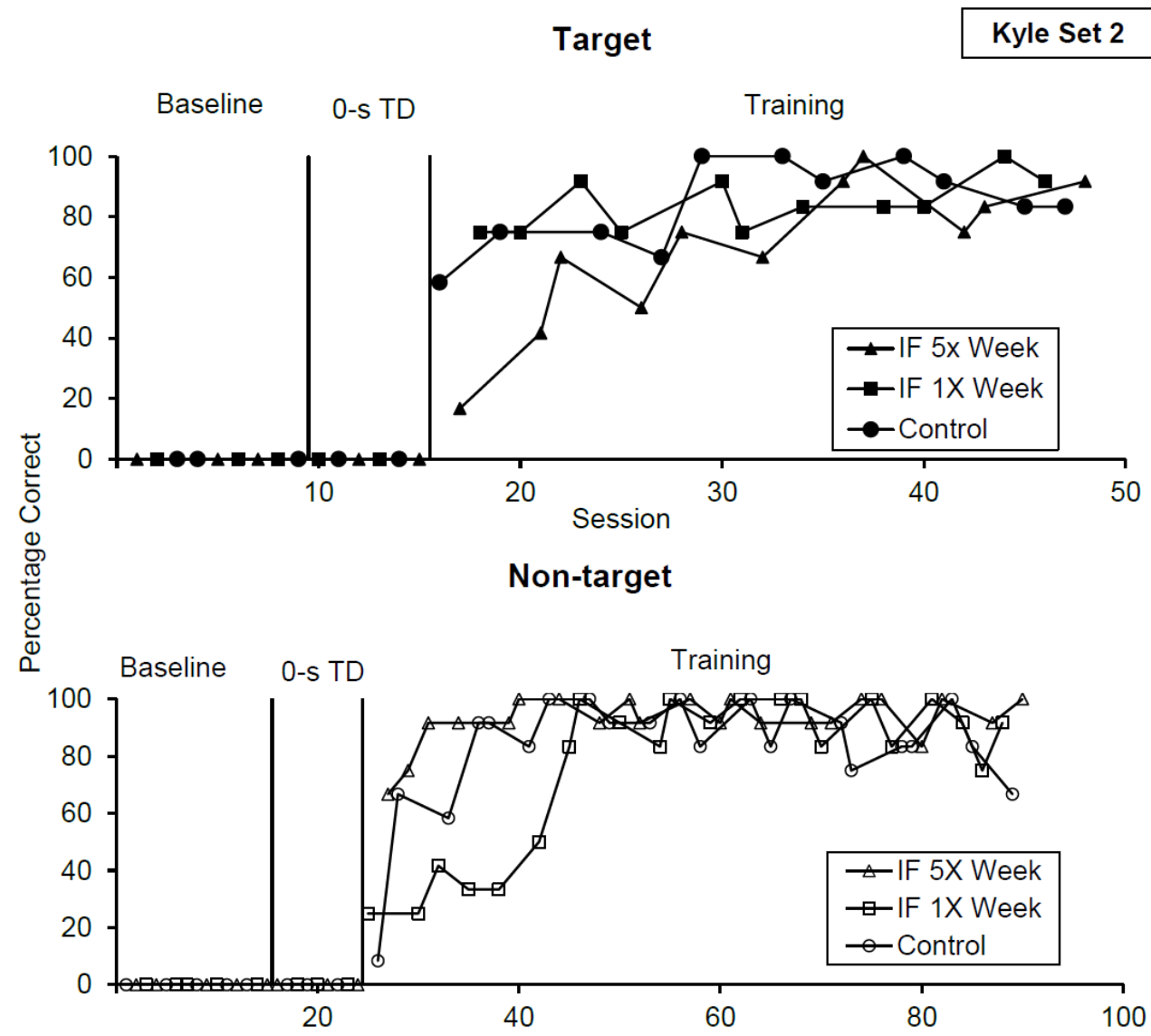

Echoic Responses

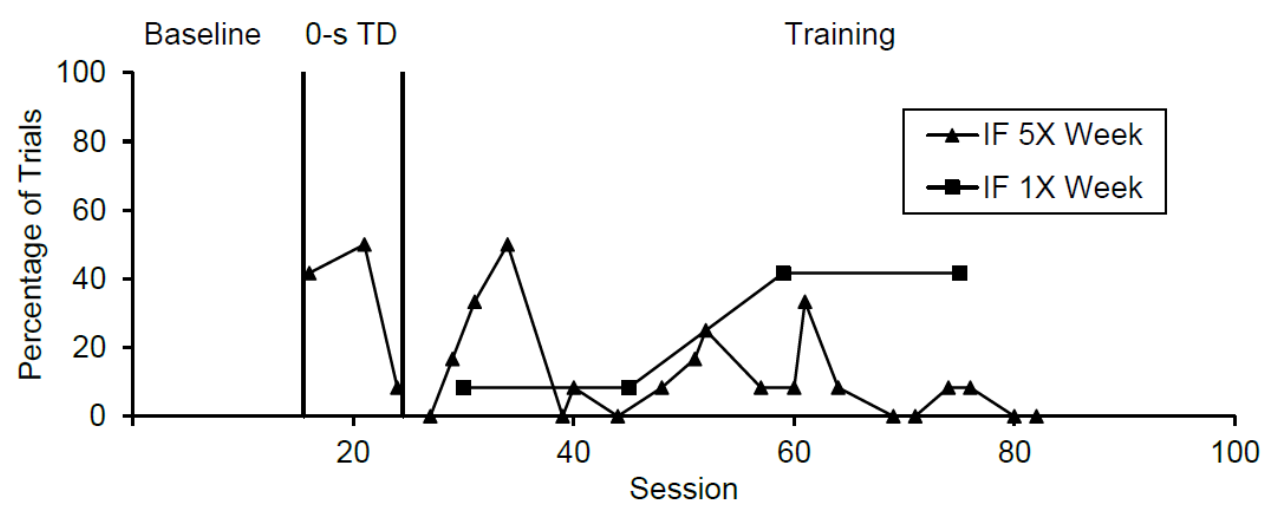

Figure 6. Percentage of trials with a correct response during teaching sessions with target (first panel) and non-target (second panel) responses, as well as percentage of trials with an echoic response for target responses during teaching sessions for non-target responses with instructive feedback (third panel) for Kyle Set 2. 
Kyle Set 2
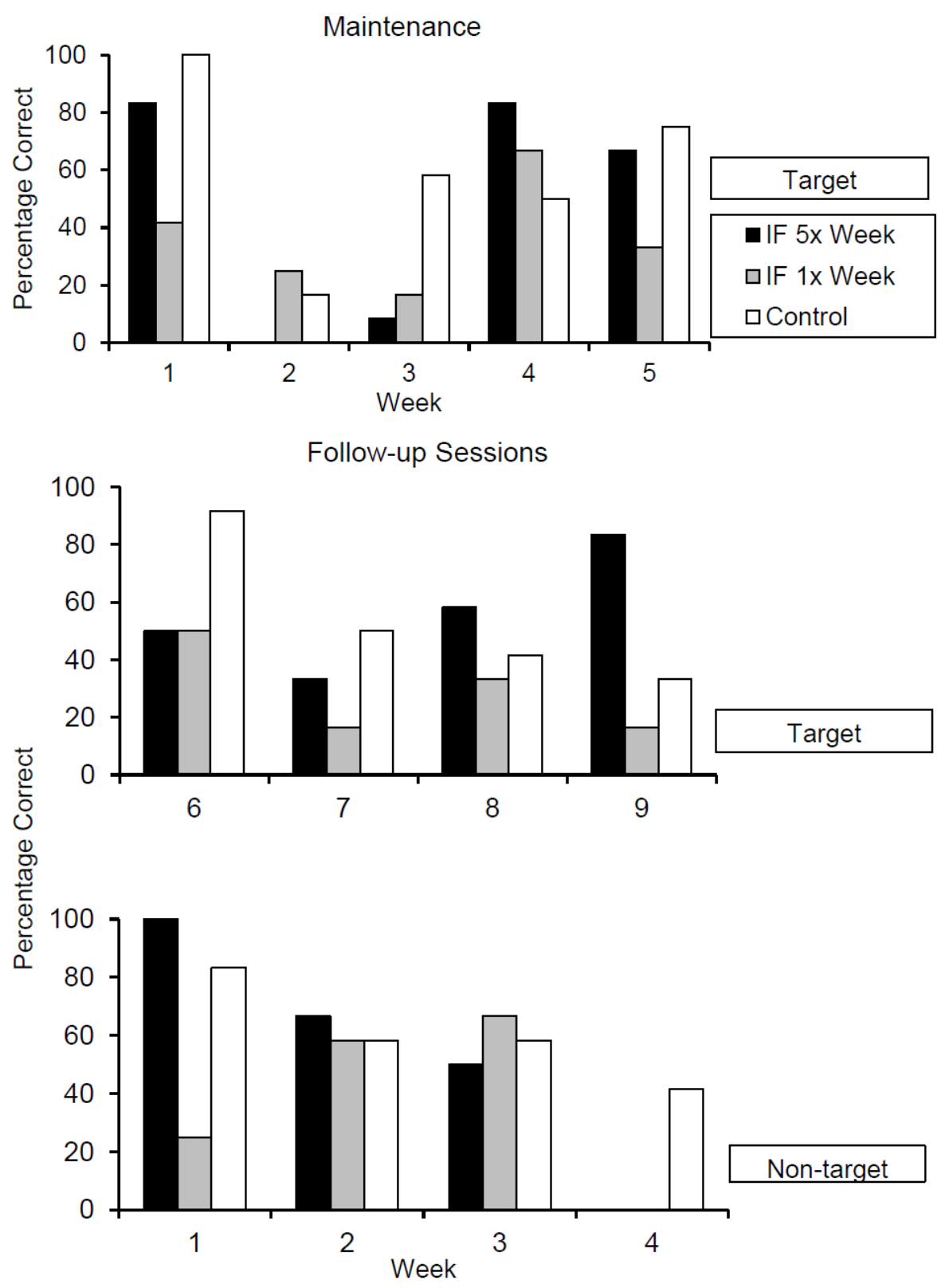

Figure 7. Average percentage of trials with a correct response during weekly maintenance sessions for target responses (first panel) and weekly follow-up sessions for target (second panel), and non-target responses (third panel) for Kyle Set 2. 


\section{Appendix A}

\section{Glossary}

Autism spectrum disorder (ASD): a neurodevelopmental disorder characterized by persistent deficits in social communication and social interactions across contexts, as well as restricted, repetitive patterns of behavior, interests, and activities.

Constant-prompt delay: a teaching procedure that involves gradually increasing the delay between the presentation of the skill targeted for instruction and controlling prompt.

Discrete-trial instruction (DTI): a highly structured, one-on-one teaching procedure commonly used in early intervention programs.

Early-intensive behavioral intervention (EIBI): a time intensive (40 hours per week) evidencebased procedure that uses the principles of behavior analysis to teach adaptive behaviors to young children with autism spectrum disorders.

Error-correction procedures: a procedure used to correct for errors during discrete-trial instruction. This procedure involves presenting a controlling prompt to help the child respond correctly to the instruction.

Instructive feedback: a teaching procedure that involves presenting secondary targets (i.e., extra non-target skills) during a learning trial. The therapist does not require a response to secondary targets, and if the child does respond, the therapist does not provide differential consequences.

Receptive skill: responding correctly to an instruction that does not require a vocal response.

Reinforcement thinning: reducing how frequently the therapist provides a specific consequence that serves to increase or maintain responding during teaching sessions.

Response maintenance: the persistence of a response across time, and in the absence of some or all procedures that were used to teach that response.

Task interspersal: a teaching procedure that involves alternating between presenting previously learned skills and new skills, typically according to a pre-specified ratio. The therapist requires a response to previously learned skills, and provides differential consequences for responding. 
Appendix B

Operational Definitions

\begin{tabular}{|l|l|}
\hline \multicolumn{1}{|c|}{$\begin{array}{c}\text { Child } \\
\text { Response }\end{array}$} & \multicolumn{1}{c|}{ Definition } \\
\hline Verbal & $\begin{array}{l}+=\text { Child states or approximates (must match approximations listed or be more } \\
\text { phonetically similar to the correct response) the correct name of picture within } 5 \mathrm{~s}(+/- \\
\text { 2s) of looking at the card. } \\
\text { E = Child states or approximates the incorrect name of the picture, provides an } \\
\text { approximation } \text { not } \text { on the protocol that is not more phonetically similar to the correct } \\
\text { response, segments (e.g., pauses between sounds/repeats sounds) or elongates (e.g., } \\
\text { extends any one sound }>1 \mathrm{~s}) \text { the name of the picture, or emits a sound that begins with a } \\
\text { different phoneme than the name of the picture within } 5 \mathrm{~s}(+/-2 \mathrm{~s}) \text { of looking at the card. } \\
\text { NR = Child does not say anything within } 5 \mathrm{~s}(+/-2 \mathrm{~s}) \text { of looking at the picture. }\end{array}$ \\
\hline $\begin{array}{l}+=\text { Child echoes or approximates (must match approximations listed or be more } \\
\text { phonetically similar to the correct response) the therapist's model within } 5 \mathrm{~s}(+/-2 \mathrm{~s}) . \\
\mathrm{E}=\text { Child echoes the therapist's model with an approximation not listed on the protocol } \\
\text { within } 5 \mathrm{~s}(+/-2 \mathrm{~s}) .\end{array}$ \\
$\mathrm{NR}=$ Child does not echo the therapist's model within $5 \mathrm{~s}(+/-2 \mathrm{~s})$.
\end{tabular}

General Session

\begin{tabular}{|l|l|l|}
\hline \multicolumn{2}{|c|}{ Therapist Response } & \multicolumn{1}{c|}{ Definition } \\
\hline 1 & Instruction (SD) & The therapist does not present an instruction. \\
\hline 2 & $\begin{array}{l}\text { Attending to } \\
\text { Instructional } \\
\text { Stimulus }\end{array}$ & The child looks at (prompted or unprompted) the instructional stimulus. \\
\hline
\end{tabular}




\begin{tabular}{|c|c|c|}
\hline \multicolumn{3}{|c|}{ Baseline/Maintenance/Follow-up Sessions } \\
\hline & apist Response & Definition \\
\hline 3 & Prompt & $\begin{array}{l}\text { The therapist does not provide a controlling prompt following a correct } \\
\text { response, incorrect response, or no response. }\end{array}$ \\
\hline 4 & $\begin{array}{l}\text { Reinforcement } \\
(\mathrm{SR}+)\end{array}$ & $\begin{array}{l}\text { The therapist does not provide praise or access to a preferred item for } \\
\text { correct, incorrect, or no response. }\end{array}$ \\
\hline 5 & $\begin{array}{l}\text { Programmed } \\
\text { Reinforcement } \\
\text { (VR2 SR+) }\end{array}$ & $\begin{array}{l}\text { The therapist provides six opportunities for the child to earn } \\
\text { reinforcement on the trials marked on the datasheet. } \\
\text { The therapist presents a mastered task during the trial indicated on the } \\
\text { data sheet. } \\
\text { If the participant responds correctly to the mastered task the } \\
\text { therapist provides immediate (within } 2 \mathrm{~s} \text { ) praise and } 25 \mathrm{~s}(+/-5 \mathrm{~s} \text { ) } \\
\text { access to a preferred tangible/edible item. } \\
\text { If the participant responds incorrectly to the mastered task the } \\
\text { therapist models the correct response, and gives the participant } 5 \mathrm{~s} \\
\text { to echo the correct response. If the participant echoes the correct } \\
\text { response the therapist provides praise and ends the trial. If the } \\
\text { participant does not echo the correct response within } 5 \mathrm{~s} \text {, the } \\
\text { therapist does not say anything and ends the trial. }\end{array}$ \\
\hline
\end{tabular}

\begin{tabular}{|l|l|l|}
\hline \multicolumn{2}{|l|}{ 0-s Prompt Delay: Targets and Non-targets } \\
\hline \multicolumn{2}{|c|}{ Therapist Response } & \multicolumn{1}{c|}{ Definition } \\
\hline 3 & Prompt & $\begin{array}{l}\text { Therapist models the correct response immediately after the child looks at the } \\
\text { picture (within 1 s). }\end{array}$ \\
\hline 4 & $\begin{array}{l}\text { Reinforcement } \\
(\mathrm{SR}+)\end{array}$ & $\begin{array}{l}\text { Following a correct prompted response the therapist provides immediate } \\
\text { (within 2 s) praise and 25 s (+/- 5 s) access preferred edible/tangible item. }\end{array}$ \\
\hline
\end{tabular}

\begin{tabular}{|c|c|c|}
\hline \multicolumn{3}{|c|}{ Training: Targets and Non-targets } \\
\hline \multicolumn{2}{|c|}{ Therapist Response } & Definition \\
\hline 3 & Prompt & $\begin{array}{l}\text { - Immediately following an incorrect response (within } 1 \mathrm{~s} \text { ) or no response } \\
\text { within } 5 \mathrm{~s}(+/-2 \mathrm{~s}) \text { of the child looking at the picture, the therapist models } \\
\text { the correct response. } \\
\text { - The therapist gives the participant } 5 \mathrm{~s} \text { to echo the correct response. If the } \\
\text { participant echoes the correct response the therapist provides neutral } \\
\text { praise. } \\
\text { The therapist then removes the instructional stimulus and re-presents the } \\
\text { trial until the participant engages in a correct unprompted response or a } \\
\text { maximum of } 20 \text { error-correction trials. } \\
\text { - The therapist does not provide a prompt following a correct response. }\end{array}$ \\
\hline 4 & $\begin{array}{l}\text { Reinforcement } \\
(\mathrm{SR}+)\end{array}$ & $\begin{array}{l}\text { Following a correct response or during an error correction trial the } \\
\text { therapist provides immediate (within } 2 \mathrm{~s} \text { ) praise and } 25 \mathrm{~s}(+/-5 \mathrm{~s}) \text { access } \\
\text { to a preferred edible/tangible item. }\end{array}$ \\
\hline
\end{tabular}




\begin{tabular}{|l|l|}
\hline & $\begin{array}{l}\text { Once reinforcement is removed for error correction: The therapist } \\
\text { provides only praise for correct responses on error-correction trials. } \\
\text { The therapist does not provide reinforcement following an incorrect } \\
\text { response. }\end{array}$ \\
\hline
\end{tabular}

\begin{tabular}{|c|c|c|}
\hline \multicolumn{3}{|c|}{ Instructive Feedback } \\
\hline & $\begin{array}{l}\text { Therapist } \\
\text { Response }\end{array}$ & Definition \\
\hline 3 & Prompt & $\begin{array}{l}\text { - Immediately following an incorrect response (within } 1 \mathrm{~s}) \text { or no response } \\
\text { within } 5 \mathrm{~s}(+/-2 \mathrm{~s}) \text { of the child looking at the picture, the therapist models the } \\
\text { correct response. } \\
\text { - The therapist gives the participant } 5 \mathrm{~s} \text { to echo the correct response. If the } \\
\text { participant echoes the correct response the therapist provides neutral praise. } \\
\text { The therapist then removes the instructional stimulus for and re-presents the } \\
\text { trial until the participant engages in a correct unprompted response or a } \\
\text { maximum of } 20 \text { error-correction trials. } \\
\text { - The therapist does not provide a prompt following a correct response. }\end{array}$ \\
\hline 4 & $\begin{array}{l}\text { Reinforcement } \\
(\mathrm{SR}+)\end{array}$ & $\begin{array}{l}\text { - Following a correct response or during an error correction trial the therapist } \\
\text { provides immediate (within } 2 \mathrm{~s} \text { ) praise and } 25 \mathrm{~s} \text { access preferred } \\
\text { edible/tangible item }(+/-5 \mathrm{~s}) \text {. } \\
\text { - Once reinforcement is removed for error correction: The therapist provides } \\
\text { only praise for correct responses on error-correction trials. } \\
\text { - The therapist does not provide reinforcement following an incorrect response. }\end{array}$ \\
\hline 5 & $\begin{array}{l}\text { Instructive } \\
\text { Feedback }\end{array}$ & $\begin{array}{l}\text { If the child engages in a correct response: } \\
\text { - Immediately after providing praise (within } 2 \mathrm{~s} \text { ) the therapist provides a } \\
\text { vocal model of a previously mastered target stimulus. } \\
\text { If the child engages in a correct response during error correction (and } \\
\text { reinforcement is removed for error correction): } \\
\text { - Immediately after providing praise (within } 2 \mathrm{~s} \text { ) the therapist provides a } \\
\quad \text { vocal model of a previously mastered target stimulus }\end{array}$ \\
\hline 6 & Echo & $\begin{array}{l}\text { The therapist does not provide praise, does not say anything, and does not show a } \\
\text { change in facial expression (e.g., smile) if the child echoes the therapist's vocal } \\
\text { model during instructive feedback for } 5 \mathrm{~s} \text {. }\end{array}$ \\
\hline 7 & $\begin{array}{l}\text { Attending to } \\
\text { Instructive } \\
\text { Feedback } \\
\text { stimulus }\end{array}$ & $\begin{array}{l}\text { The child looks at (prompted or unprompted) each target stimulus prior to the } \\
\text { therapist providing a vocal model of the previously mastered target stimulus. }\end{array}$ \\
\hline
\end{tabular}




\section{Appendix C}

\section{Sample Primary Data Sheet}

Date Condition:

Prompt: Session: Time: D.C.

\begin{tabular}{|c|c|c|c|c|c|c|}
\hline Non-Target & Trial & Verbal & Model & Target & Echo & $\mathrm{SR}+$ \\
\hline Cow & 1 & + E NR & $+\mathrm{E} \mathrm{NR}$ & Key & $\begin{array}{ll}\mathrm{Y} & \mathrm{N}\end{array}$ & $\mathrm{Y} \mathrm{N}$ \\
\hline Juice & 2 & $+\mathrm{E} \mathrm{NR}$ & $+\mathrm{E} \mathrm{NR}$ & Truck & $\mathrm{Y} \quad \mathrm{N}$ & $\mathrm{Y} \quad \mathrm{N}$ \\
\hline Marker & 3 & $+\mathrm{E} \mathrm{NR}$ & $+\mathrm{E} \mathrm{NR}$ & Drum & $\mathrm{Y} \quad \mathrm{N}$ & $\mathrm{Y} \quad \mathrm{N}$ \\
\hline Marker & 4 & $+\mathrm{E} \mathrm{NR}$ & $+\mathrm{E} \mathrm{NR}$ & Truck & $\mathrm{Y} \quad \mathrm{N}$ & $\mathrm{Y} \quad \mathrm{N}$ \\
\hline Juice & 5 & $+\mathrm{E} \mathrm{NR}$ & $+\mathrm{E} \mathrm{NR}$ & Drum & $\mathrm{Y} \quad \mathrm{N}$ & $\mathrm{Y} \quad \mathrm{N}$ \\
\hline Cow & 6 & $+\mathrm{E} \mathrm{NR}$ & $+\mathrm{ENR}$ & Key & $\mathrm{Y} \quad \mathrm{N}$ & $\mathrm{Y} \mathrm{N}$ \\
\hline Juice & 7 & $+\mathrm{E} \mathrm{NR}$ & $+\mathrm{E} \mathrm{NR}$ & Drum & $\mathrm{Y} \quad \mathrm{N}$ & $\mathrm{Y} \quad \mathrm{N}$ \\
\hline Cow & 8 & $+\mathrm{E} \mathrm{NR}$ & $+\mathrm{E} \mathrm{NR}$ & Key & $\begin{array}{ll}\mathrm{Y} \quad \mathrm{N} \\
\end{array}$ & $\mathrm{Y} \mathrm{N}$ \\
\hline Marker & 9 & $+\mathrm{E} \mathrm{NR}$ & $+\mathrm{E} \mathrm{NR}$ & Truck & $\mathrm{Y} \quad \mathrm{N}$ & $\mathrm{Y} \quad \mathrm{N}$ \\
\hline Cow & 10 & $+\mathrm{E} \mathrm{NR}$ & $+\mathrm{E} \mathrm{NR}$ & Truck & $\mathrm{Y} \quad \mathrm{N}$ & $\mathrm{Y} \mathrm{N}$ \\
\hline Marker & 11 & $+\mathrm{E} \mathrm{NR}$ & $+\mathrm{ENR}$ & Key & $\mathrm{Y} \quad \mathrm{N}$ & $\mathrm{Y} \quad \mathrm{N}$ \\
\hline Juice & 12 & $+\mathrm{E} \mathrm{NR}$ & $+\mathrm{E} \mathrm{NR}$ & Drum & $\mathrm{Y} \quad \mathrm{N}$ & $\mathrm{Y} \quad \mathrm{N}$ \\
\hline
\end{tabular}




\section{Appendix D}

\section{Sample Secondary Data Sheet}

Date Condition:

Prompt: Session: Time: D.C.

\begin{tabular}{|c|c|c|c|c|c|cc|}
\hline Non-Target & Trial & Verbal & Model & Target & Echo & \multicolumn{2}{|c|}{ SR+ } \\
\hline Cow & 1 & + E NR & + E NR & Key & Y N & Y N \\
\hline Juice & 2 & + E NR & + E NR & Truck & Y N & Y N \\
\hline Marker & 3 & + E NR & + E NR & Drum & Y N & Y N \\
\hline Marker & 4 & + E NR & + E NR & Truck & Y N & Y N \\
\hline Juice & 5 & + E NR & + E NR & Drum & Y N & Y N \\
\hline Cow & 6 & + E NR & + E NR & Key & Y N & Y N \\
\hline Juice & 7 & + E NR & + E NR & Drum & Y N & Y N \\
\hline Cow & 8 & + E NR & + E NR & Key & Y N & Y N \\
\hline Marker & 9 & + E NR & + E NR & Truck & Y N & Y N \\
\hline Cow & 10 & + E NR & + E NR & Truck & Y N & Y N \\
\hline Marker & 11 & + E NR & + E NR & Key & Y N & Y N \\
\hline Juice & 12 & + E NR & + E NR & Drum & Y N & Y N \\
\hline
\end{tabular}

\begin{tabular}{|c|c|c|c|c|c|c|c|}
\hline $\begin{array}{c}\text { Att. } \\
\text { Non-target }\end{array}$ & SD & Prompt & SR+ & IF & $\begin{array}{c}\text { Att. } \\
\text { Target }\end{array}$ & Echo & EC \\
\hline$+\mathrm{E}$ & $+\mathrm{E}$ & $+\mathrm{E}$ & $+\mathrm{E}$ & $+\mathrm{E}$ & $+\mathrm{E}$ & $+\mathrm{E} \mathrm{NA}$ & \\
\hline$+\mathrm{E}$ & $+\mathrm{E}$ & $+\mathrm{E}$ & $+\mathrm{E}$ & $+\mathrm{E}$ & $+\mathrm{E}$ & $+\mathrm{E} \mathrm{NA}$ & \\
\hline$+\mathrm{E}$ & $+\mathrm{E}$ & $+\mathrm{E}$ & $+\mathrm{E}$ & $+\mathrm{E}$ & $+\mathrm{E}$ & $+\mathrm{E} \mathrm{NA}$ & \\
\hline$+\mathrm{E}$ & $+\mathrm{E}$ & $+\mathrm{E}$ & $+\mathrm{E}$ & $+\mathrm{E}$ & $+\mathrm{E}$ & $+\mathrm{E} \mathrm{NA}$ & \\
\hline$+\mathrm{E}$ & $+\mathrm{E}$ & $+\mathrm{E}$ & $+\mathrm{E}$ & $+\mathrm{E}$ & $+\mathrm{E}$ & $+\mathrm{E} \mathrm{NA}$ & \\
\hline$+\mathrm{E}$ & $+\mathrm{E}$ & $+\mathrm{E}$ & $+\mathrm{E}$ & $+\mathrm{E}$ & $+\mathrm{E}$ & $+\mathrm{E} \mathrm{NA}$ & \\
\hline$+\mathrm{E}$ & $+\mathrm{E}$ & $+\mathrm{E}$ & $+\mathrm{E}$ & $+\mathrm{E}$ & $+\mathrm{E}$ & $+\mathrm{E} \mathrm{NA}$ & \\
\hline$+\mathrm{E}$ & $+\mathrm{E}$ & $+\mathrm{E}$ & $+\mathrm{E}$ & $+\mathrm{E}$ & $+\mathrm{E}$ & $+\mathrm{E} \mathrm{NA}$ & \\
\hline$+\mathrm{E}$ & $+\mathrm{E}$ & $+\mathrm{E}$ & $+\mathrm{E}$ & $+\mathrm{E}$ & $+\mathrm{E}$ & $+\mathrm{E} \mathrm{NA}$ & \\
\hline$+\mathrm{E}$ & $+\mathrm{E}$ & $+\mathrm{E}$ & $+\mathrm{E}$ & $+\mathrm{E}$ & $+\mathrm{E}$ & $+\mathrm{E} \mathrm{NA}$ & \\
\hline$+\mathrm{E}$ & $+\mathrm{E}$ & $+\mathrm{E}$ & $+\mathrm{E}$ & $+\mathrm{E}$ & $+\mathrm{E}$ & $+\mathrm{E} \mathrm{NA}$ & \\
\hline$+\mathrm{E}$ & $+\mathrm{E}$ & $+\mathrm{E}$ & $+\mathrm{E}$ & $+\mathrm{E}$ & $+\mathrm{E}$ & $+\mathrm{E} \mathrm{NA}$ & \\
\hline
\end{tabular}

